\title{
Designing mixtures of varieties for multifunctional agriculture with the help of ecology. A review
}

\author{
Sébastien Barot ${ }^{1}$ - Vincent Allard ${ }^{2}$ - Amélie Cantarel ${ }^{3}$. Jérôme Enjalbert ${ }^{4}$. \\ Arnaud Gauffreteau ${ }^{5}$ - Isabelle Goldringer ${ }^{4}$ Jean-Christophe Lata ${ }^{1,6}$. \\ Xavier Le Roux ${ }^{3} \cdot$ Audrey Niboyet $^{1} \cdot$ Emanuelle Porcher $^{7}$
}

Accepted: 8 February 2017 / Published online: 4 April 2017

(C) INRA and Springer-Verlag France 2017

\begin{abstract}
The study of natural ecosystems and experiments using mixtures of plant species demonstrates that both species and genetic diversity generally promote ecosystem functioning. Therefore, mixing crop varieties is a promising alternative practice to transform modern high-input agriculture that is associated with a drastic reduction of within-field crop genetic diversity and is widely recognized as unsustainable. Here, we review the effects of mixtures of varieties on ecosystem functioning, and their underlying ecological mechanisms, as studied in ecology and agronomy, and outline how this knowledge can help designing more efficient mixtures. We recommend the development of two complementary strategies to optimize variety mixtures by fostering the ecological mechanisms leading to a positive relationship between biodiversity and
\end{abstract}

Sébastien Barot

sebastien.barot@ird.fr

1 IEES-P (IRD, CNRS, UPEC), 7 quai Saint Bernard - Bât A - 7e étage - CC 237, 75005 Paris, France

2 INRA, UMR 1095 Génétique, Diversité et Ecophysiologie des Céréales, 234 Avenue du Brézet, 63100 Clermont-Ferrand, France

3 UMR CNRS 5557, UMR 1418 INRA, Ecologie Microbienne, Université Lyon1, Université de Lyon, Villeurbanne, France

4 UMR 0320 (INRA-CNRS-UPS) Génétique Végétale, 91190 Gif-sur-Yvette, France

5 INRA, UMR 211 Agronomie, AgroParisTech, Université Paris-Saclay, 78850 Thiverval-Grignon, France

6 Department of Geoecology and Geochemistry, Institute of Natural Resources, Tomsk Polytechnic University, Lenin Avenue, 30, 634050 Tomsk, Russia

7 UMR 7204, Centre d'Ecologie et des Sciences de la Conservation, Sorbonne Universités-MNHN-CNRS-UPMC, Muséum national d'Histoire naturelle, CP135, 43 rue Buffon, 75005 Paris, France ecosystem functioning and its stability through time, i.e., sampling and complementarity effects. (1) In the "trait-blind" approach, the design of high-performance mixtures is based on estimations of the mixing abilities of varieties. While this approach is operational because it does not require detailed trait knowledge, it relies on heavy experimental designs to evaluate mixing ability. (2) The trait-based approach is particularly efficient to design mixtures of varieties to provide particular baskets of services but requires building databases of traits for crop varieties and documenting the relations between traits and services. The performance of mixtures requires eventually to be evaluated in real economic, social, and agronomic contexts. We conclude that the need of a multifunctional lowinput agriculture strongly increases the attractiveness of mixtures but that new breeding approaches are required to create varieties with higher mixing abilities, to foster complementarity and selection effects through an increase in the variance of relevant traits and to explore new combinations of trait values.

Keywords Biodiversity $\cdot$ Mixtures of varieties $\cdot$ Sampling effect - Complementarity effect - Crop breeding · Crop traits . Multifunctional agriculture $\cdot$ Mixing ability

\section{Contents}

1. Introduction

2. Ecological mechanisms that would lead to positive impacts of mixtures of varieties

2.1 Links between species diversity and ecosystem functioning

2.2 Necessary conditions for positive effects of mixtures of varieties

2.3 Potential sampling effects in mixtures of varieties

2.4 Potential complementarity and facilitation effects in mixtures of varieties 
2.5 Responses to global environmental changes and disturbances of mixtures of varieties

2.6 Potential negative effects of mixtures of varieties

3. How can ecology guide the design of mixtures of varieties?

3.1 Blind-screening of variety mixtures

3.2 Towards a trait-based approach for assembling varieties to maximize crop yield

3.3 How can we guide the assemblage of varieties to deliver baskets of services?

4. Importance of the agricultural context

4.1 Constraints and opportunities for the development of new mixtures of existing varieties

4.2 Criteria for the assessment of mixture performance

4.3 Influence of agricultural practices

4.4 New breeding strategies for mixtures of varieties

5 Conclusion and perspectives

Acknowledgments

References

\section{Introduction}

It is widely recognized in ecology that biodiversity can strongly influence ecosystem functioning. Typically, many experiments have manipulated species richness in experimental plant communities (usually grassland communities) and shown that primary production and total plant biomass generally increase with species richness (Hector et al. 2010; Hector et al. 1999; Scherber et al. 2010; Tilman et al. 1996). Some of these experiments have also documented a decrease in the variability of ecosystem production with species richness (Gross et al. 2014; Hector et al. 2010). Furthermore, several studies have shown that species richness may also influence the way plant communities respond to global environmental changes (Reich et al. 2004) or disturbances (Tilman and Downing 1994). Though most previous studies focused on species richness, significant genetic diversity exists within plant species (Cianciaruso et al. 2009) and has now been shown to play an important role for ecosystem functioning (Hughes et al. 2008). For example, litter decomposition depends on the genotypic richness of cottonwoods (Schweitzer et al. 2005). Plant genetic diversity is also known to influence the presence and abundance of organisms such as soil organisms, aboveground predators, or herbivores (Chateil et al. 2013; Johnson et al. 2006; Parker et al. 2010; Wimp et al. 2004), which in turn likely influences plant populations. Plant genetic diversity can ultimately influence plant productivity (Cook-Patton et al. 2011; Kotowska et al. 2010) and resistance to disturbances (Hughes and Stachowicz 2004; Parker et al. 2010).
Despite the potential benefits of biodiversity, agriculture has historically and progressively reduced species richness and genetic diversity within species to increase yields under high-input conditions. Twenty major crops (from a total of 2500 domesticated plant species) currently cover $44 \%$ of arable land (Leff 2004). Within-field biodiversity is now usually reduced to one genetically homogeneous cultivated species and the number of cultivated species and varieties is likely to have decreased both at the regional and global scales (Bonnin et al. 2014; Østergård et al. 2009). FAO (2010) estimates that $75 \%$ of crop diversity has been lost between 1900 and 2000. This decrease is tightly linked to the selection of improved varieties adapted to intensive agricultural practices (Loeuille et al. 2013; Tester and Langridge 2010). Nevertheless, it is more and more recognized that current high-input agricultural practices are not sustainable (Foley et al. 2011; Tilman et al. 2002) because they are based on huge amounts of artificial inputs (mostly fertilizers and pesticides), irrigation, and practices that tend to degrade soil fertility and the functioning of non-cultivated ecosystems. In particular, it has been shown that increasing, or even maintaining, crop yields becomes more difficult with extreme climate events and the need to decrease fertilizer use, as demonstrated for wheat in France over the 1950-2010 period (Brisson et al. 2010).

Alternative more sustainable agricultural systems thus need to be developed especially in the present climate change context (Howden et al. 2007). A general idea, in the line of agroecology, ecological engineering, or nature-based solutions (Altieri 1989; Barot et al. 2012; Eggermont et al. 2015; Malézieux 2011), is to increase the biodiversity of cultivated systems to mimic, to a certain extent, natural ecosystems and hopefully benefit from this biodiversity in terms of yield, stability, or sustainability (Altieri 1999; Gaba et al. 2015; Østergård et al. 2009). This approach can be developed in different ways that have often already been explored empirically in traditional agricultural systems, e.g., cover crops, associated crops, agro-forestry, complex crop rotations, mixtures of varieties, and on-farm management of genetic diversity. Indeed, traditional practices tend to maintain a higher genetic diversity than modern high-input agriculture (Jarvis et al. 2008). Such practices remain grounded in empirical knowledge and their actual effectiveness has not been thoroughly scientifically tested, so that they remain largely underused in modern agriculture. Research should thus be undertaken to better understand the mechanisms through which plant diversity and, especially, within-field genetic diversity may be beneficial in cropping systems.

Here, we analyze how ecological knowledge can help optimize a specific practice that has been rekindled by sustainability concerns, i.e., variety mixtures, by predicting its effects on the functioning of agro-ecosystems and by designing efficient mixtures increasing or stabilizing yields and providing 
other ecosystem services. Ecosystem services are the benefits provided by ecosystem to humans. Obviously, the first service provided by agro-ecosystems is the provision of food, but we use here the notion of ecosystem service to emphasize that agro-ecosystems can provide other services, e.g., carbon storage, regulation of green-house gases, maintenance of soil fertility.... Our general rationale follows four steps: (1) We list ecological mechanisms through which mixtures of varieties could be beneficial in terms of yield and ecosystem services. To do so, we summarize the knowledge gained from ecological experiments manipulating plant species or genetic diversity. Then, we use this knowledge to describe how mixtures of varieties could be designed. (2) We explain how the assessment of the mixing ability of varieties can be used to choose varieties to be included in a mixture. (3) We present how ecology uses plant traits, measured under standardized conditions, to predict the effects of these plants on ecosystem functioning and advocate that it could be possible to use the same approach to design mixtures of varieties with high yields or leading to the provision of particular baskets of services. (4) Finally, we highlight that the development of mixtures of varieties in agriculture cannot only rely on ecological results obtained in natural ecosystems, raising the particular constraints and opportunities associated with agriculture for the development of efficient mixtures. The ideas we develop are potentially relevant for the mixtures of varieties in any type of crop (vegetables, fruit trees, cereals...) but we mainly focus on small grain cereals for which more results are available (Fig. 1).

\section{Ecological mechanisms that would lead to positive impacts of mixtures of varieties}

\subsection{Links between species diversity and ecosystem functioning}

The impact of biodiversity on ecosystem functioning has extensively been studied through manipulations of species richness. This has led to a wealth of experimental studies and a comprehensive general framework, most of which can also be transposed to within-species genetic diversity, which is our focus here. Positive effects of species richness on ecosystem functioning (especially biomass production, we hereafter use the term production for biomass production in natural ecosystems and for the yield in agro-ecosystems) have been shown to arise due to two types of mechanisms (Loreau and Hector 2001) that can be disentangled through a variance partitioning approach (Loreau 1998): sampling effects and complementarity between species. Sampling effects (Fig. 2, left) arise because communities with more species are more likely to host species that perform the best in a given environment. This requires that the more productive species dominate

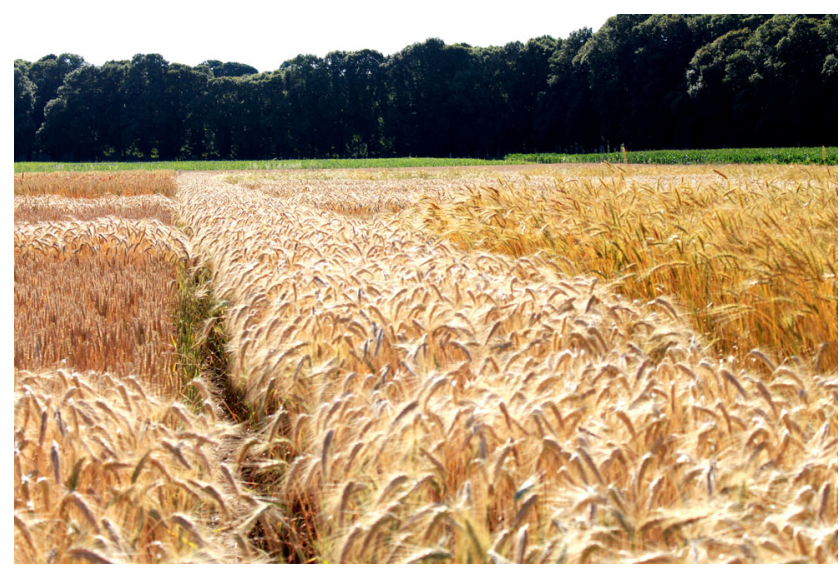

Fig. 1 Photos of experimental plots of mixtures of bread wheat separated by a border of triticale

the community in terms of biomass or space occupancy, so that sampling effects are also called selection effects. Sampling effects lead to overyielding, i.e., on average diverse communities are more productive than the mean production of monocultures. In a constant environment, knowledge on the best performing species is enough to obtain a highly productive ecosystem. However, sampling effects occur both in space and time because environmental conditions vary among locations (e.g., due to soil properties) and years (e.g., due to climate) so that the best performing species is generally not the same across space and time. Complementarity effects (Fig. 2, right) arise because of complementarity in the resource use or the ecological niches of different species (e.g., for soil mineral resources, Bessler et al. 2009; Scherer-Lorenzen et al. 2003) and/or because of facilitation between species (e.g., legumes providing nitrogen to non-legumes, Spehn et al. 2002). These effects may increase total ecosystem biomass production, sometimes leading to a production higher than that of the most productive monoculture. This is called transgressive overyielding.

Both sampling and complementarity effects may lead to an insurance effect of diversity (Fig. 2, bottom) when examining the effect of biodiversity across time (Loreau 2000; Yachi and Loreau 1999). First, the temporal mean of production may increase (1) through a sampling effect because more diverse communities are more likely to host well-performing species at any time, (2) because diverse communities foster complementarity effects at any time. Second, asynchrony in species response to environmental variability due to temporal niche differentiation, which combines a kind of temporal complementarity effect and a sampling effect at any time, may also lead to a buffering effect decreasing the temporal variability of the production in more diverse communities.

All these mechanisms have been well documented in plant communities, for which biomass production depends on the number of species (Cardinale et al. 2003; Hector 


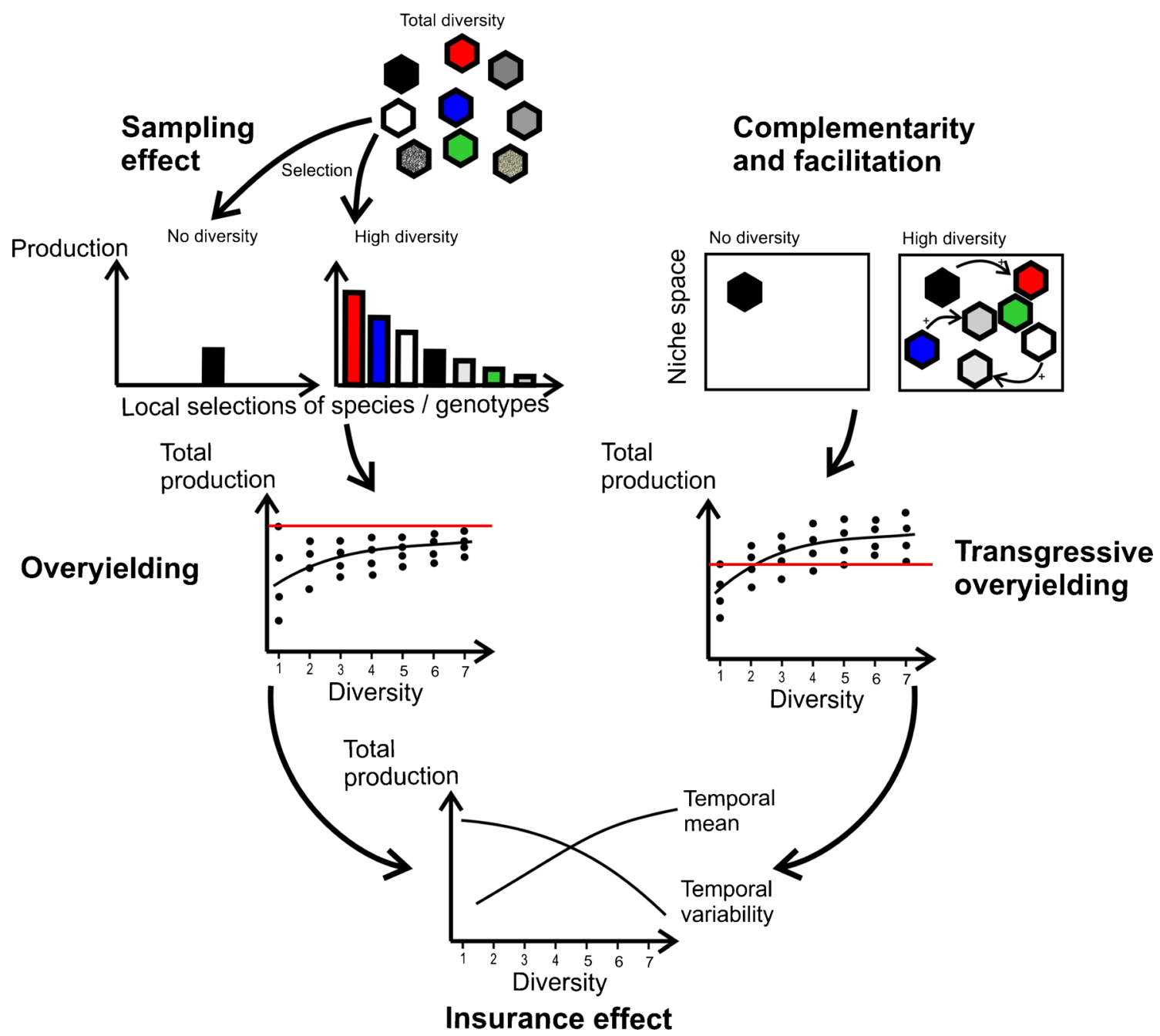

Fig. 2 General description of the mechanisms through which biodiversity influences plant production. In the top left part of the figure, the two frames represent the total niche space. Hexagons represent species or varieties. In the histogram, each bar represents a

et al. 2010; Hector et al. 2007; Latz et al. 2012) and should apply to mixtures of varieties within agricultural fields. Indeed, in all the rationales analyzing effects of species richness, the term "species" can be replaced by "varieties," as soon as there is enough functional diversity between varieties (see below). However, it is necessary to assess which mechanisms more likely apply to mixtures of varieties and to what extent one can expect a positive influence of mixtures of varieties in cropping systems. Note also that published results suggest that effects of the number of genotypes highly depend on the considered system. Some find significant effects of the number of genotypes on biomass production (Cook-Patton et al. 2011; Kotowska et al. 2010), others find small (Aanderud and Bledsoe 2009) or no effect (Fridley and Grime 2010), others only find an effect of the number of genotypes on the stability of biomass production (Prieto et al. 2015). species or variety. The red horizontal lines denote the maximum production of varieties growing in pure stands (only one species or one variety)

\subsection{Necessary conditions for positive effects of mixtures of varieties}

Positive effects of species richness on plant production rely on functional differences between species (Díaz and Cabido 2001; Garcia-Palacios et al. 2011; Loreau 2004; Tilman et al. 1997). If all species had exactly the same functional characteristics, they would be functionally redundant and mixing them would not lead to any positive effect either through complementarity or sampling effect. Functional diversity should be lower with variety mixtures than with species-rich plant communities, and mixtures should be assembled using varieties that are functionally different enough. Crop varieties may for instance differ in their timing of growth and rooting depth (Richards 2000), but also in their resistance to diseases (Zhu et al. 2000) and to drought (Witcombe et al. 2008), as well in their mycorrhizal dependence (Hetrick et al. 1992). 
Trade-offs between functional characteristics should also be very influential for the effect of mixtures of varieties. Trade-offs indeed often impede a single variety to combine all desired functional characteristics. In particular, allocation trade-offs imply that resources invested into one function cannot be invested into another. For example, investment into the root system could decrease investment into leaves or grains. Investment of carbohydrates to sustain an efficient mycorrhizal network could lead to a decrease in the allocation of carbohydrates to growth or to root exudates. Similarly, allocation of resources to defenses against herbivores should also decrease the resources allocated to other functions such as growth (Herms and Mattson 1992). Ecological trade-offs (Strauss et al. 2002) may also be very influential because they constrain the balance between various ecological interactions such as above-belowground interactions. For example, chemical defenses against herbivores might decrease the mineralization activities of soil microorganisms (Grime et al. 1996) or limit associations with mycorrhizal fungi (de Roman et al. 2011). Besides, because of these trade-offs, it is impossible to select a generalist super-variety that could gather all the desirable characteristics of specialist varieties. Generalist varieties tend to bear costs that impede them to perform each of their ecological functions as efficiently as specialist varieties.

\subsection{Potential sampling effects in mixtures of varieties}

Sampling effects triggered by mixtures of varieties would rely on three necessary conditions to be useful in agriculture. First, environmental conditions (climate, nutrient availability, presence and abundance of organisms facilitating or hindering crop growth) should vary in space and time. Otherwise, farmers could easily select the best performing variety to cultivate under the prevailing environmental conditions. Second, varieties should respond differently to these fluctuating environmental conditions. These first two conditions are probably easily met. Third, the varieties that are best adapted to local conditions, and outcompete other varieties during a given year, should be the ones that increase most the targeted function. This is generally straightforward with biomass production (the largest or tallest plants generally outcompete other plants), but sampling effects can be weaker, and even negative, when the biomass or competitive ability of a species/ variety are poor indicators of their ecosystem functions (Jiang et al. 2008). In natural multi-species communities, the dominance of the most adapted species can arise because seeds are often produced in excess so that the most successful species may occupy more space and use more resource than could be predicted by their mere relative abundance during the preceding growing season. Similarly, in these natural communities, competition could allow the best performing species to outcompete other species and preempt a higher share of resources. These mechanisms are likely mitigated in cropping systems because varieties are sown at the optimum density to occupy the whole space and each variety is likely to be sown at the same density. Anyway, the best performing varieties could have a disproportionate positive impact on yield if their seed germinate better, and if plasticity in growth (e.g., through tillering, root foraging, and aerial architecture) allow these varieties to preempt more resources than other varieties, in comparison to what could be predicted by the initial equal sowing densities of all varieties. This should arise because of mechanisms allowing for asymmetric competition (Weiner 1990) between plants. Results obtained in mixtures of grassland species confirm that plasticity and the ability to increase the number of "modules" per individuals through tillering is a key mechanism of positive biodiversity effects (Marquard et al. 2009). This suggests that crops or varieties with high tillering abilities such as most wheat varieties could benefit more from mixtures of varieties than crops that have a much lower ability for tillering such as maize. Finally, results obtained on barley have already shown that mixing varieties may stabilize production through a better adaptation to environmental variability (Kiær et al. 2012).

\subsection{Potential complementarity and facilitation effects in mixtures of varieties}

The most documented positive interaction between varieties is a reduction of pathogen or pest impacts in mixtures of varieties with contrasting resistance levels, via a facilitation-like mechanism (Wolfe 1985, Zhu et al. 2000, Tooker et al. 2012). Within-field genetic diversity may decrease the impact of pathogens in several ways: (1) by diluting pathogen propagules that are dispersed among susceptible varieties; (2) by blocking the spread of pathogens thanks to a barrier effect of resistant individuals; (3) by inducing a higher genetic diversity in the pathogen at the field scale, which may in turn induce resistance in the crop; (4) on the longer term, by slowing the evolutionary adaptation of the pathogen to resistant varieties, which may reduce the need for the constant renewal of resistant varieties (Loeuille et al. 2013).

Any functional difference allowing for complementarity in resource use between varieties should allow mixtures of varieties to better exploit resources such as water, mineral nutrients, or light, which would in turn allow mixtures to have a higher productivity or resistance to environmental hazards than fields planted with a single variety. For example, differences in straw length in mixtures of barley varieties have been shown to increase production (Kiær et al. 2012). However, such functional mechanisms have so far been poorly documented in mixtures of varieties and most data come from species mixtures, with many cases addressing plant architecture. For example, mixing a variety with many lateral roots with a variety with fewer lateral roots but with deeper roots, could allow a better use of water or nutrients and fertilizers 
(Lynch and Brown 2012). This could subsequently lead to a better resistance to drought, which is likely an important feature under climate change. In the same vein, a trade-off between scale and precision in foraging for light (canopy architecture) or nutrients (root system architecture) has been documented (Campbell et al. 1991). This suggests that mixing varieties with the ability to track long-lasting coarse-scale patches of resources, together with varieties with the ability to track more-ephemeral and finer-scale patches of resources, could be beneficial. Some examples of such complementarity for the use of nutrients have been documented only at the species level, either in intercropping systems ( $\mathrm{Li}$ et al. 2014; Postma and Lynch 2012) or in experimental grasslands (Bessler et al. 2009; Fornara and Tilman 2009). Furthermore, if mineral nutrients are better exploited by mixtures of varieties, this could also reduce several environmental impacts, e.g., nitrate leaching into groundwater and the subsequent pollution in neighboring ecosystems.

Indeed, nutrient cycling could potentially lead to facilitation effects between varieties (Hajjar et al. 2008) because many plant-mediated soil processes increase the availability of resources that become available for any individual plant of the stand. Plants can foster mineralization through rhizosphere priming effect (Shahzad et al. 2015) and solubilize phosphorus (Hinsinger 2001). They may also inhibit nitrification, which increases the long-term availability of nitrogen (Boudsocq et al. 2009; Lata et al. 2004). Mineral nutrients can also be transferred between plant individuals through the mycorrhizal networks (Wilson et al. 2006). Through all these mechanisms, some varieties could thus increase the availability of nutrients for other varieties in a mixture. Again, such effects have only been documented for inter-specific interactions especially in intercropping systems (Hauggaard-Nielsen and Jensen 2005; Li et al. 2007; Li et al. 2014) and grasslands (Le Roux et al. 2013). Nevertheless, it has already been shown that plant genotype strongly influences soil microbial community (Schweitzer et al. 2008) so that microorganism-mediated complementarity between varieties is possible.

\subsection{Responses to global environmental changes and disturbances of mixtures of varieties}

Changing environmental conditions may increase the positive effects of mixtures of varieties in terms of production and provision of ecosystem services. First, and as specified above, changing environmental conditions are necessary for eliciting sampling effects. Second, some complementary effects may appear only under specific environmental conditions, e.g., under extreme climatic conditions (Callaway et al. 2002; Hautier et al. 2014). Hence, the current context of global environmental changes and increase in the frequency and severity of extreme climate events such as heat waves or drought (IPCC 2013) may reinforce the positive effects of mixtures of varieties. Such increased sampling and complementary effects in a changing environment have already been documented in plant communities. More diverse grassland communities show greater stimulation of plant biomass in response to elevated $\mathrm{CO}_{2}$ and increased atmospheric $\mathrm{N}$ deposition than less diverse grassland communities (Reich et al. 2004), which has mostly been attributed to complementary effects. Similarly, more diverse grassland communities have a higher resistance and resilience to drought events than less diverse grasslands (Tilman and Downing 1994). These effects have been attributed to sampling effects, diverse ecosystems being more likely to contain some species that can maintain their growth or biomass during a disturbance, thus compensating for negative effects on other species. All these effects should also apply to mixtures of varieties, thereby contributing to the adaptation of agriculture to climate change (Howden et al. 2007).

\subsection{Potential negative effects of mixtures of varieties}

While mixing varieties may be beneficial in terms of production or stabilization of production, it may also lead to negative effects. The first risk of mixing varieties is obviously to introduce varieties that have suboptimal performances (performance being defined in the article as the overall merit of a cropping system, which can be described by its yield and the other ecosystem services it provides), without triggering beneficial sampling and complementarity effects. Interactions between varieties could also lead to negative effects. For example, while mixing varieties is generally expected to disfavor pathogens (when mixing varieties with different levels of resistance to pathogens) and favor pest predators, the reverse is also possible, which would result in higher damages by pathogens and pests. Indeed, if beneficial organisms could be favored by mixtures (for example because a mixture can provide a more suitable and diverse habitat through changes in canopy architecture), pathogen and pests could also be promoted by mixtures. Similarly, while interactions between particular varieties could increase the efficiency of soil resource use (e.g., through a complementarity in the use of soil resources or more efficient microbial communities involved in $\mathrm{N}$ and $\mathrm{P}$ cycling), the reverse could also be possible (e.g., through an increase in the intensity of competition for soil resources or less-efficient microbial communities). Guidelines for selecting varieties to be mixed are thus needed as well as more researches on underlying ecological mechanisms.

\section{How can ecology guide the design of mixtures of varieties?}

Because of potential negative effects and because triggering sampling and complementarity effects in mixtures of varieties requires a careful choice of varieties, criteria have to be 
developed to design mixtures. Two non-exclusive strategies can be proposed to detect the best variety combinations (Gaba et al. 2015): "blind screening" of a wide range of randomly assembled varieties vs. trait-based approaches to choose interesting mixtures.

\subsection{Blind-screening of variety mixtures}

The "trait-blind" approach, where mixtures (mainly binary mixtures) are optimized on the basis of their observed performances, has been subject to previous theoretical work, through the development of the "mixing ability" concept. The value of the mixture results from interactions between the involved varieties described as general mixing ability (GMA) or specific mixing ability (SMA), i.e., the mean value of all mixtures including a given genotype, and the specific interaction between two components, respectively. The statistical analysis of mixing ability derives from the seminal work of Sprague and Tatum (1942) and Griffing (1956) to analyze single-cross performance, which has been adapted and further developed for cultivar mixtures (as reviewed in Dawson and Goldringer 2012; Gizlice et al. 1989). As GMA effect reflects both the innate productive ability of a genotype in pure stand plus, its separate ability to affect mixture response through competition, Gizlice et al. (1989) further partitioned GMA into two components, respectively called genotype performing ability (GPA) and true general mixing ability (TGMA). According to Knott and Mundt (1990), the performance $Y_{i j k}$ of the mixture of genotypes $i$ and $j$, with equal frequencies, in replication $k$ can be expressed as:

$$
\begin{aligned}
Y_{i j k}= & \mu+\mathrm{GPA}_{i}+\mathrm{GPA}_{j}+\mathrm{TGMA}_{i}+\mathrm{TGMA}_{j}+\mathrm{SMA}_{i j} \\
& +e_{i j k}
\end{aligned}
$$

where $\mu$ is the average of the trial, GPA the performance of each variety in pure stand, TGMA the deviation of GMA (as defined above) from the GPA, and $e_{i j k}$ is the random residual. Hence, partitioning GMA into GPA and TGMA can only be achieved by using the pure stand of the components and analyzing mixing response (Gizlice et al. 1989). Note that an important challenge is now to better understand the ecological mechanisms behind the TGMA and the SMA and to link this decomposition of yield to the decomposition into selection and complementarity effects of biodiversity (Loreau and Hector 2001). The impact of competition/compensation during the growth of wheat mixtures and the consequences on disease severity have for example been analytically addressed (Finckh and Mundt 1992).

When exploring the combining ability within a set of available varieties, the main issue is to test the different possible variety combinations. While it is problematic when considering binary mixtures $(n(n-1) / 2$ possible combinations with $n$ varieties), it becomes impossible with more components in the mixture. Predicting $n$-way mixture performance from the two-way mixture performance was suggested by Knott and Mundt (1990) and further developed by Lopez and Mundt (2000) on the basis of the theoretical approach presented by de Miranda-Filho (de Miranda-Filho and Chaves 1991) for selecting composites. This procedure appeared efficient when tested on wheat mixtures built with five club wheat cultivars (Lopez and Mundt 2000), i.e., it predicted well the best combinations of varieties with a reduced number of mixtures handled. Note that an advantage of this approach based on mixing abilities is that it does not require to be able to separate the biomass or grain production of each variety of a mixture at harvest, contrary to the variance partitioning approach developed by Loreau (1998). On the reverse, the variance partitioning approach but not the mixing ability approach allows assessing the complementarity and sampling effects.

\subsection{Towards a trait-based approach for assembling varieties to maximize crop yield}

Trait-based approaches are increasingly used in ecology to link biodiversity to ecosystem functioning and services (Lavorel and Garnier 2002) and could guide the design of adequate variety mixtures to deliver single or multiple agroecosystem services: each variety can be described by its functional traits, which determines its impact on ecological functions and ultimately the ecosystem services provided by the variety (de Bello et al. 2010; Violle et al. 2007). Functional traits are morphological, ecophysiological or phenological characteristics of plant species or varieties that may influence ecosystem or agro-ecosystem functions and ultimately the delivery of services.

The traditional approach of artificial selection targets a few traits such as lodging resistance, tillering ability, and seed mass because they are considered important for yield. However, maximizing the values of all targeted traits is sometimes not possible because of the existence of trade-offs between traits at the individual plant level, and because a single variety unlikely holds all the favorable trait values (Fig. 3a). The trait-based approach can help overcome this issue and guide the design of beneficial mixtures of varieties for maximizing yield (Fig. 3c). In this case, a pool of varieties characterized for their functional traits can be chosen to maximize the set of values for different traits relevant for yield. This can provide novel sets of trait values within fields partly releasing the trade-offs that exist between some traits (Fig. 3c).

Indeed, the feasibility of the trait-based approach depends on the availability of values for a range of varieties and relevant traits, which is currently a limiting factor (but see del Pozo et al. 2014; Nakhforoosh et al. 2014) and would require considerable efforts in agriculture (Martin et al. 2015). In addition, the types of traits to be considered and trait values to be 


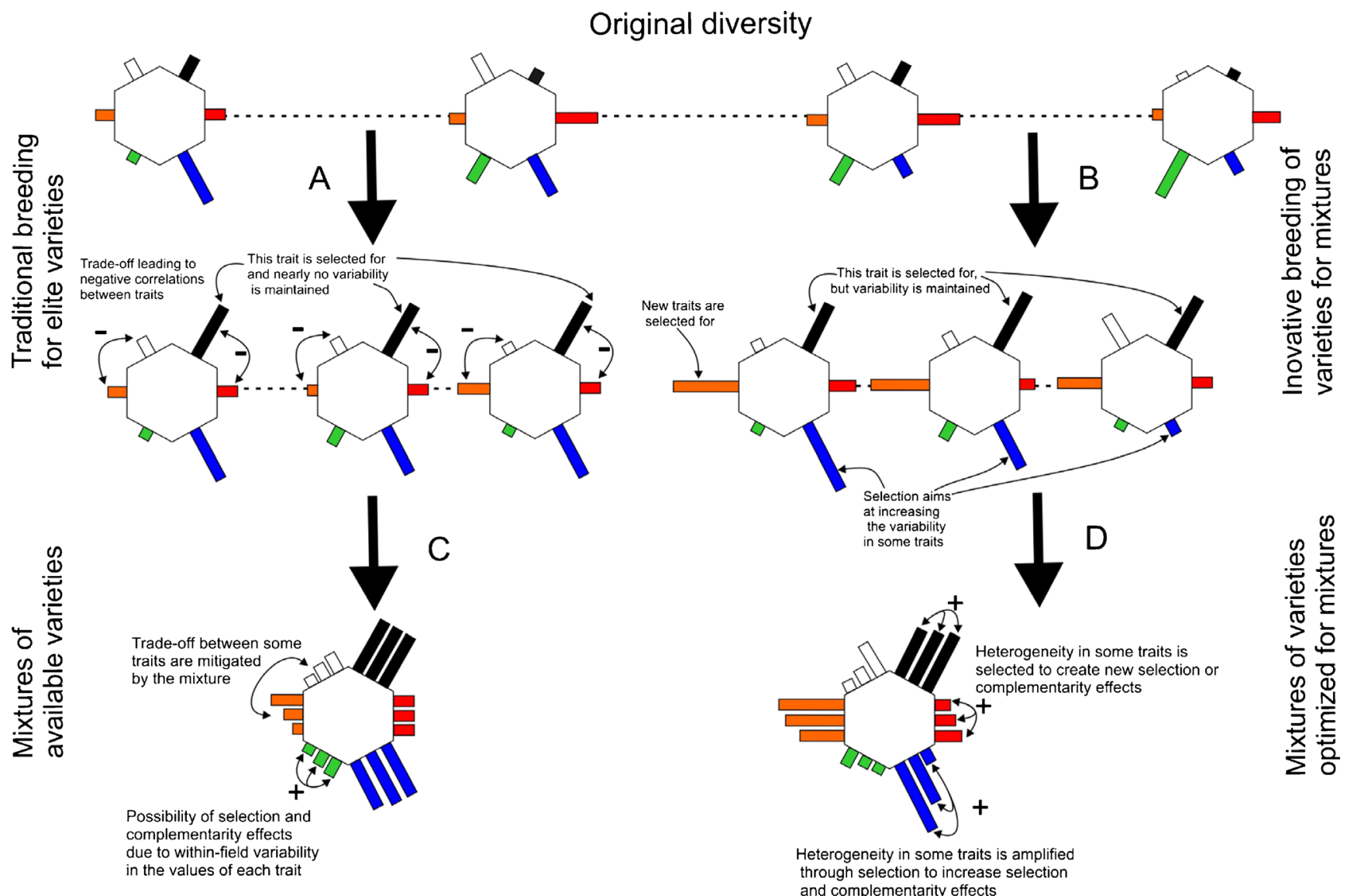

Fig. 3 Comparison of the effects of different approaches on trait variability within a field and consequences in terms of services. Each hexagon represents a crop variety growing in pure stand or a mixture of crop variety. Each side of the hexagon represents a different trait and colored bars along these sides represent different trait values so that there is only one bar along each side for pure stands and several bars for mixtures. We assume that trait values are normalized so that higher trait values are favorable for the targeted ecosystem service. a The traditional breeding approach targets a limited number of traits. b

selected likely depend on agricultural practices. For instance, under non-optimal conditions such as low nutrient availability, specific functional traits such as the absorption capacity of mineral $\mathrm{N}$ forms (nitrate vs. ammonium) by roots may become important. Whereas agronomic trials may have identified varieties performing well under these suboptimal conditions (Wissuwa et al. 2008), the main relevant traits influencing crop performance are most of the time not documented.

Furthermore, the trait-based approach requires highthroughput screening of variety traits using standardized protocols as performed for plant species (Cornelissen et al. 2003; Kattge et al. 2011; Pérez-Harguindeguy et al. 2013). Given that trait values associated with a given variety can depend on local abiotic and biotic conditions and agricultural practices, it would thus be important to screen variety traits under contrasted conditions relevant for high versus low chemical inputs, or contrasted pedoclimatic conditions.
Breeding might allow optimizing varieties for mixtures. c Varieties can be mixed to obtain novel sets of functional traits at the mixture scale. d Mixing varieties that have been optimized for mixtures can allow enhancing sampling and complementarity effects through increases in within-field trait variability. These four approaches can be compared both in terms of yield and ecosystem services because sampling and complementarity effects potentially affect all ecosystem services (see Fig. 4)

It must be added that plant growth and plant traits are plastic so that varieties growing in mixtures are likely to have trait values different from the trait values they would display in single variety stands. Indeed, plasticity is well known in agriculture (see for example Dornbusch et al. 2011) and results on inter-specific mixtures show that inter-specific competition and the identity of neighbors shape this plasticity (Abakumova et al. 2016; Burns and Strauss 2012). Furthermore, plasticity could also increase complementarity for resource exploitation (Burns and Strauss 2012; Zhu et al. 2015). This suggests that we must also acquire knowledge on the variability of traits and that basing the choice of varieties to be mixed only on traits measured in single variety stands might be misleading. Moreover, this confirms that plasticity is likely an important characteristic to be sought in varieties chosen for mixtures. 


\subsection{How can we guide the assemblage of varieties to deliver} baskets of services?

Modern agriculture should be more sustainable and multifunctional, and able to produce a range of amenities. Innovative agricultural practices are thus increasingly expected to provide various ecosystem services including not only yield and grain/ fodder quality but also maintenance of soil fertility, carbon sequestration and mitigation of climate change, disease regulation and pest control, regulation of water cycle and water purification, conservation of biodiversity, esthetic value of landscapes for tourism, and human health (Zhang et al. 2007).

In this context, it is expected that increasing the geneticand ultimately functional - diversity of crops could be of paramount importance (Fig. 4). Indeed, ecological studies for grasslands and forests indicate that the positive role of biodiversity increases when multiple ecological functions or multiple services are considered (Allan et al. 2013; Gamfeldt et al. 2013; Hector and Bagchi 2007; Isbell et al. 2011; Zavaleta et al. 2010). The key challenge is thus to design variety mixtures that perform well to deliver baskets of services instead of single services.

The trait-based approach (Fig. 3) to maximize yield can be expanded to guide the design of variety mixtures delivering particular baskets of services (Fig. 5). The main idea is that particular baskets of agro-ecosystem services are linked to particular combinations of traits and trait values, i.e., sets of traits associated with the mixtures of crop varieties. These sets of traits could be described by the means and variances of traits within a mixture, or more complex indexes of functional diversity (Mouchet et al. 2010). For instance, if crop yield, biocontrol of weeds, and resistance to phyto-pathogens are three main services to be delivered, the main trait values in the variety mixtures to be chosen may include relative growth rate (RGR), precocity, soil coverage capacity, and traits related to resistance to pathogens. Then, it might be found that to improve the provision of these three services, a mixture must

\section{Sum of all services}

\section{provided by the mixture}

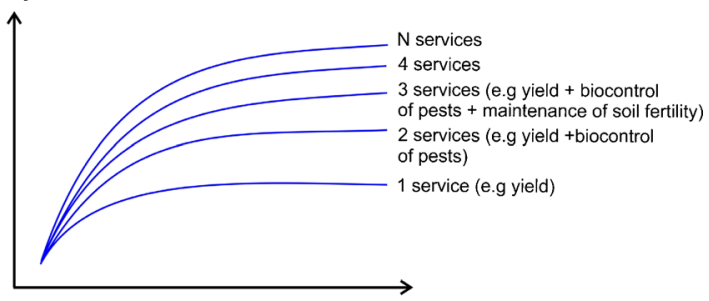

Number of varieties

Fig. 4 Expected effects of the number of varieties of a mixture on the total production of services, when a single service or several services are considered. This figure was inspired by the results obtained for grassland and forest species (Hector and Bagchi 2007; Isbell et al. 2011; Zavaleta et al. 2010) that highlight the increasing importance of plant diversity when an increasing number of services are to be delivered
A Traits of a single variety Basket of services
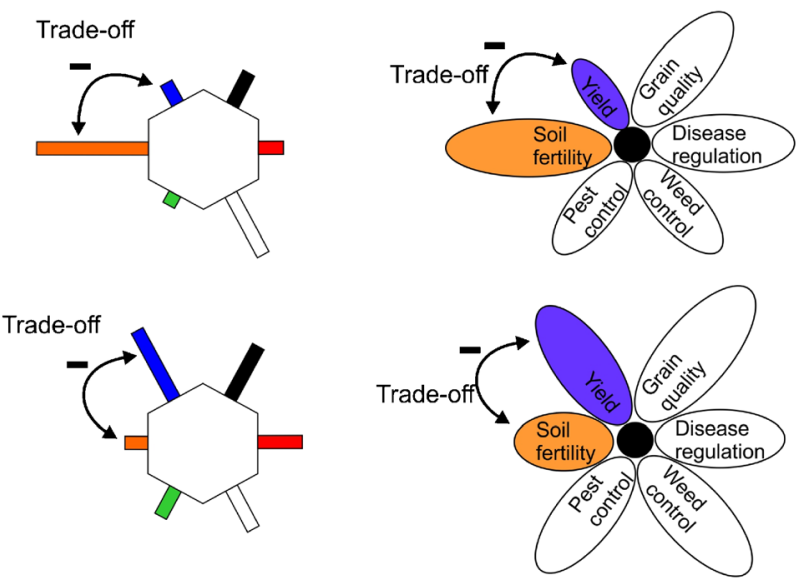

\section{B Traits of a mixture of two varieties}

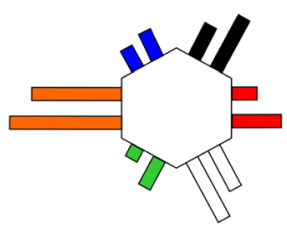

\section{Basket of services}
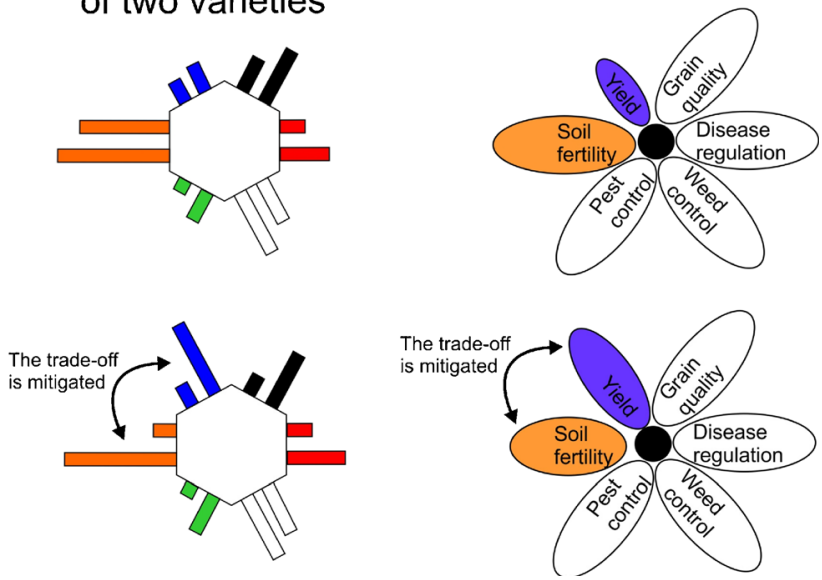

Fig. 5 Trait-based approach and the delivering of baskets of services for a single variety (a) and a mixture of varieties (b). As in Fig. 3, each hexagon is a mixture of varieties or a single variety and bars along hexagon sides are trait values. The combination of services provided is determined by the combination of trait values and, in the case of a mixture, by the combination of means and variances of trait values. a A negative trade-off between traits that determine different agro-ecosystem services (here yield and soil fertility) explain that fields planted with a single variety cannot properly deliver these different services resulting in trade-offs between services. b Mixing crop varieties can allow obtaining new sets of traits, and some mixtures and associated trait sets can overcome trade-offs between agro-ecosystem services

have the following: a high mean RGR and precocity, and a high variance in soil coverage capacity and resistance to pathogens. In contrast, if crop yield, maintenance of soil fertility, biocontrol of pests, and agro-biodiversity conservation are the main services targeted, choosing varieties for mixtures should focus on traits such as RGR, specific root length, root affinity, and absorption capacity for ammonium and nitrate and traits fostering the biodiversity of the targeted organisms. Variety assemblage rules should thus be guided so as to obtain mixtures with favorable trait syndromes. Of course, lack of knowledge on the range of relevant traits and trait syndromes 
needed to deliver particular baskets of services is currently a limiting factor here. However, recent studies have initiated the identification of plant traits important for a range of single services, including not only yield but also soil fertility (Cantarel et al. 2015; Laughlin 2011).

Using the existing knowledge on mechanisms involved in positive effects of biodiversity likely helps facing this challenge. Mixtures of varieties and their traits should foster complementarity/facilitation and sampling effects (see above) to provide services (and not only the yield). Table 1 describes some trait combinations that should be sought to increase the provision of particular services through complementarity or sampling effects. The varieties should be different enough, which can be characterized by high variances for the relevant traits. Sampling effects also require the compensation between varieties in time and space. This should involve traits allowing for plasticity (e.g., tillering ability) in growth and differences between varieties in their responses to environmental variability. Complementarity effects should be fostered by high variances in traits linked to the use of soil resources and light. Possibly, high variances in some architectural traits could also modify the structure of the crop cover and impact the microclimate in and below the cover. This could in turn change the occurrence of various organisms living in the crop. If the suitable traits are well assembled, this could decrease the occurrence of some pests and increase the occurrence of organisms feeding on pests. All these mechanisms are supported by general rationales but still have to be documented, apart from the positive impact of the variability in resistance to pathogens that has been shown to reduce the impact of pathogens (see above). However, the trait approach has already been shown to be successful to predict biomass production or ecological functions in mixtures of species (Cantarel et al. 2015; de Bello et al. 2010; Quetier et al. 2007).

Interestingly, mixing varieties could help overcome some trade-offs between agro-ecosystem services. A pool of varieties can be chosen to provide novel types of trait syndromes within crop fields, which could partly release the trade-offs that normally exist between agro-ecosystem services when using single varieties (Fig. 5). Future variety assembling rules will thus have to be clear on the types of baskets of services to be delivered.

\section{Importance of the agricultural context}

The knowledge acquired on experimental and natural ecosystems outside the context of agriculture is not sufficient to design high-performance mixtures because agriculture is associated with various constraints and opportunities that could reduce or increase our ability to use mixtures in different agricultural sectors and the ultimate benefits of mixtures. First, cropping systems impose constraints on the diversity of characteristics of varieties grown together and mixtures must be suitable for crop management practices. Second, the way to assess the performance of a mixture must be carefully thought and likely depends on the type of agriculture. Moreover, while ecological results on the positive impact of biodiversity have often been obtained without comparing different environmental conditions, the diversity of agricultural practices offers a vast field of investigation. Indeed, the impact of mixtures, as well as the impact of different varieties in pure stands (Murphy et al. 2007), likely tightly depends on these practices. Third, along the selection of cultivated varieties, a huge diversity of varieties has already been created with diverse characteristics and this diversity may be exploited to optimize mixtures of varieties (see Section 3). However, it is also feasibleand probably needed - to select new varieties that would allow fostering ecological mechanisms enhancing the performance of mixtures.

\subsection{Constraints and opportunities for the development of new mixtures of existing varieties}

A prerequisite for sound mixture design is to define their specifications, i.e., build a weighted sum of targeted services to be provided by mixtures in a given production system (agronomic, ecological, and socio-economic context). Defining specifications for mixtures also provides their evaluation framework and therefore corresponds to the first step of the ideotyping exercise as revisited by (Debaeke et al. 2014). To define those specifications, the positive and negative impacts of using mixtures not only on management practices in the farm but also on the harvest use must be properly described. Selling mixtures instead of pure varieties may be a constraint in some specialized sectors (industrial baking, brewing, malting...) because mixtures may lead to heterogeneous grain quality within a harvest while these sectors tend to use a limited number of varieties with some specific characteristics. These varieties are either used in pure stands or mixed after harvest in controlled proportions. Using mixtures (in which the proportion of each variety at harvest is not controlled) in those sectors is sometimes impossible and at least generates some additional costs: grains must be sampled and analyzed to adjust mixtures of grains. However, even if lucrative, those sectors are generally not major ones. Indeed, during the harvesting period, various varieties are generally mixed in storage silos without control on the proportions. The objective is generally to achieve minimal thresholds for some important characteristics (protein content, specific weight, humidity...), which is certainly compatible with the use of mixtures as shown on barley for the malting quality (Newton et al. 1998; Swanston et al. 2000) and on wheat for baking ability (Sarandon and Sarandon 1995). Sampling effects in mixtures of varieties (see Section 1 and Fig. 1) can also increase the risk of including in the mixture a variety presenting a default 


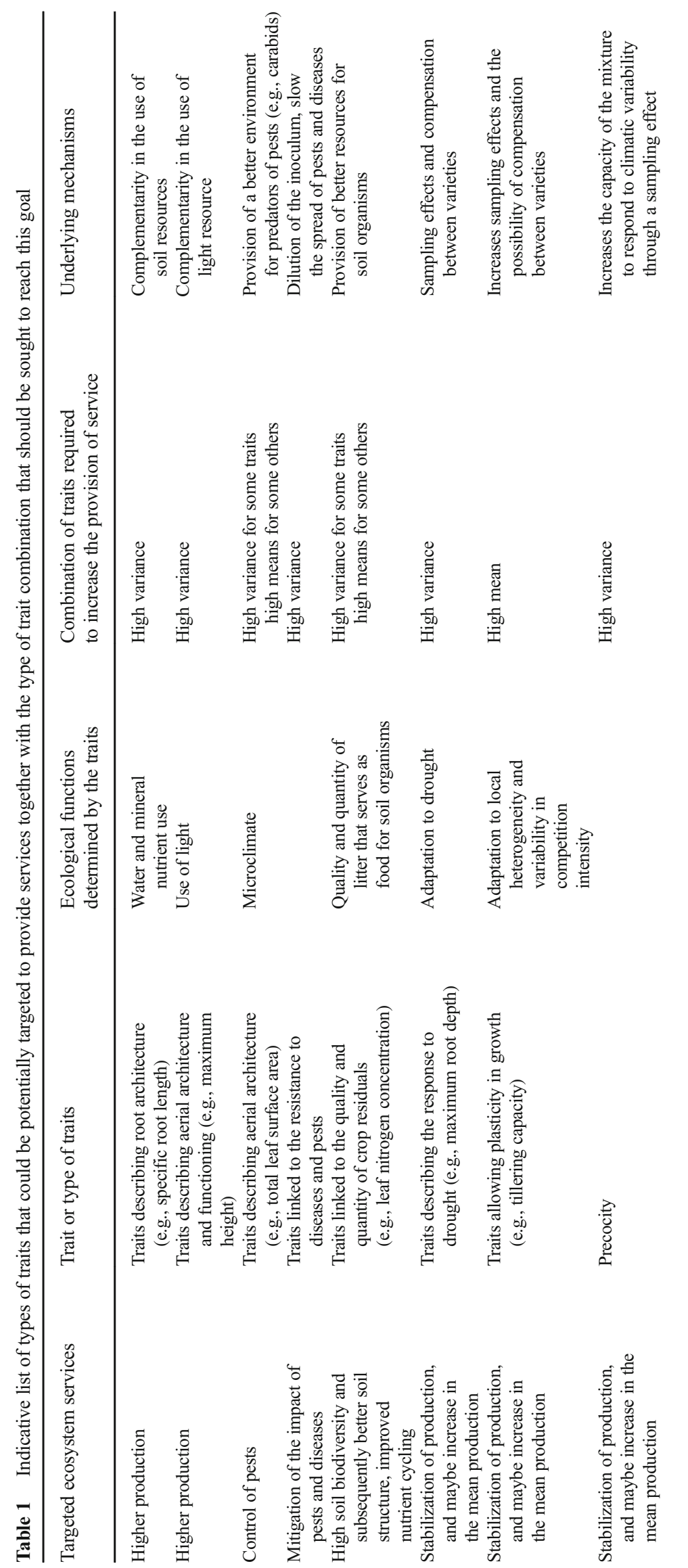


affecting the whole mixture and being an obstacle to its selling. For instance, a single variety affected by sprouting generally leads to the downgrade of the mixture.

Using mixtures in a farm also interacts with crop management practices. Usual practices and tools for real time crop management have generally been developed, studied, and implemented on homogeneous crops corresponding to one species and pure varieties. For instance, various tools based on imagery and spectrum analysis have been developed for precision agriculture to improve crop treatments and fertilization (mainly nitrogen fertilization). These tools are generally calibrated for varieties growing in pure stands and would require some additional studies and calibrations to be used in mixtures (Bavec and Bavec 2001; Debaeke et al. 2006). This is for example the case for the Hydro N-tester® (Yara), commonly used to pilot nitrogen fertilization. However, it must be noted that other tools under development for plant nitrogen measurement promote some generic calibrations (e.g., Ecarnot et al. 2013) that could be quite directly adaptable to mixtures.

Mixtures could also bring some important benefits to farmers in terms of flexibility and work organization. For instance, as diseases spread slower in a mixture than in a pure variety due to a higher diversity of resistance sources in the field (Zhu et al. 2000), farmers have more time to decide whether a pesticide application is useful and, if needed, to implement this treatment in good conditions. For instance, fungicides must be applied in strict conditions of wind, temperature, and humidity, so that the delay allowed by mixtures may facilitate the application at a favorable period, which can lead to a better efficiency of the product, a possible dose reduction and finally to a better economic and ecological balance (Finckh et al. 2000). Mixtures are also an interesting way to increase the genetic diversity at the farm scale while also decreasing the management complexity. At the farm scale, replacing pure varieties by a few mixtures maintains the overall level of genetic diversity. However, this should lead to fewer different mixtures than the number of varieties that were initially grown in pure stands, which increases the efficiency of some operations such as sowing, fertilization, and treatments. However, this reduction of the between-field variability may be considered as risky, since the underperformance of a mixture is all the more problematic that the area sown with this mixture is large. This further highlights the importance of carefully designing the rules to design variety mixtures even if higher stability of mixtures compared to pure varieties (Finckh et al. 2000; Smithson 1996) should decrease this risk of underperformance. Therefore, according to the production context, using mixture may lead to additional constraints or to more flexibility in the crop management system and the grain selling.

\subsection{Criteria for the assessment of mixture performance}

The criteria for the agronomic, socio-economic, and environmental assessment of mixtures should be adapted to local situations. In ecology and agronomy, mixtures of species or varieties are generally assessed through their ability to perform better than the mean of their varieties/species in pure stands (Kiær et al. 2009). If this criterion is relevant to measure and analyze the interactions between varieties, it is clearly not to assess the agronomic performance of mixtures. First, comparing the mixture with the mean of the mixed varieties in pure stands suggests that those pure varieties could be sown in the same field with particular local conditions, which is not done for practical reasons. Indeed, mixtures are also a way not to make a choice between varieties that are thought to behave well in a particular field. Furthermore, among the mixed varieties, some would not be cultivated in pure stand (for instance a variety sensitive to lodging that is supported by the other varieties in a mixture or a variety sensitive to one disease that is protected by the other varieties in a mixture). Mixture performance should therefore be compared to the performance of the pure variety that would have been chosen by the farmer in this field. Second, the assessment criterion depends on the motivation of the farmer to use mixtures. If a mixture is used to simplify crop management and save time, it should not be expected to perform better than pure varieties but only not to do worst. In the same vein, mixtures are often adopted to stabilize the performance and avoid unpredictable rare accidents. This means that mixtures are not always expected to perform better than pure varieties but only in some stressful situations that may be more frequent under low-input farming practices (see below). Finally, ecological experiments have often shown that high diversity leads on average to a higher production. In contrast, agriculture only requires finding a few combinations of varieties that perform especially well. This requirement is less constraining than the criterion used in ecological experiments but highlights the needs for rules and experiments to build the most performant mixtures. So far, ecology has not elaborated a framework that would allow building the best combinations of species or genotypes. This shows that there is still a lot of scientific knowledge to be developed but also suggests that the performance of mixtures could be increased in the future to an extent that it is difficult to predict.

As suggested above, mixing varieties is likely to be more beneficial if the performance of a mixture is measured through the joint assessment of various ecosystem services and amenities (including implications for management requirements for farmers), and not only using the yield. While increasing the yield or maintaining high yields often remains the goal of many agricultural researches, there are more and more pressures to develop a multifunctional agriculture (Renting et al. 2009) that provides food and other services such as the storage of carbon to mitigate climate changes. Depending on the 
development of incentives and legal constraints for a multifunctional agriculture mixing varieties might become much more desirable.

\subsection{Influence of agricultural practices}

The current knowledge gained from ecological studies on the effect of species diversity on primary production or yield suggests that facilitation and functional complementarity can play a more important role under non-optimal environmental conditions (Bertness and Callaway 1994; Callaway et al. 2002; Maestre et al. 2009). Species mixtures could perform better when the plant cover experiences stresses such as drought spells, pest bursts or lack of mineral nutrients (Hautier et al. 2014; Holmgren and Scheffer 2010; Hughes and Stachowicz 2004). Thus, the benefits of mixing varieties could be low under optimal conditions (e.g., fertilized, irrigated fields with pesticide use), where it would then be better to use the single best variety. In contrast, for maximizing yield under nonoptimal conditions (e.g., low fertilization, irrigation, and/or pesticides), some mixtures may perform better than the best varieties. This point is crucial because it is difficult to predict standard agricultural practices in 10 or 50 years. In particular, it is difficult to predict the level of inputs that will be possible, acceptable, or authorized in the future. For example, there are more and more pressures to decrease the use of pesticides. The production of nitrogen fertilizer using fossil fuels as a source of energy releases huge amounts of $\mathrm{CO}_{2}$ (Bøckman 1997) and the reserves of phosphate are likely to be exhausted within less than a century (Cordell et al. 2009). This means that it cannot be excluded that mixtures of varieties will be much more beneficial in the future and that we must now develop researches on mixtures taking into account very diverse agricultural practices and contexts. Note, however, that some results on multi-species systems suggest that increasing species diversity may be profitable on more fertile soils or with fertilization (He et al. 2002; Palma et al. 2007; Reich et al. 2001). The underlying mechanism being that, in some cases, the effect of biodiversity cannot develop when not enough resource is available. Thus, mixtures of varieties could also be performant in intensive agriculture, provided suitable varieties are used (this might require selecting new varieties, see below). Taken together, this suggests that to conclude on this issue specific experiments should be implemented manipulating at the same time the number of varieties and the amount of fertilizers.

Many types of agriculture coexist worldwide and many farmers, especially in developing countries, cannot afford inputs such as fertilizers and pesticides. These farmers have also often maintained higher level of genetic diversity for their crops than in modern high-input agriculture. This context might provide knowledge and experiences to develop mixtures in developed countries and opportunities to further develop mixtures of varieties in developing countries.

\subsection{New breeding strategies for mixtures of varieties}

Up to now, crop breeding has been mostly oriented towards the optimization of elite genotypes for pure stand performance and has never considered complementarity building in a plant cover. However, experimental evolution in grassland communities suggests that selection for niche differentiation can increase biodiversity effects via increased complementarity (Zuppinger-Dingley et al. 2014). Optimizing variety mixtures requires developing efficient methods to improve the ability of genotypes to combine with other genotypes when grown in a mixed stand and therefore to rethink the breeding schemes. So far, experiments on mixtures have used already existing varieties but optimizing mixtures and fostering complementarity and sampling effects between varieties might require combining traits that are not present in currently available varieties, precisely because they would only be favorable in mixtures (Fig. 3b). This means that it is difficult to fully assess the potential benefits of mixing varieties only using currently available varieties. This opens wide and nearly unexplored perspectives to optimize mixtures of varieties.

How to breed for mixing ability is strongly related to the "how to screen varieties" question developed in Section 3. Therefore, two main and non-exclusive approaches can be developed, i.e., "trait-based" or "trait-blind." In the absence of any knowledge on the link between variety traits and mixing ability, only the "trait-blind" method is relevant. With the full understanding of the relations between traits and selection and complementarity effects, the trait-based approach should allow the design and the breeding of sets of complementary ideotypes. In the most likely intermediate situation, trait knowledge can be used to select in progenies a subset of lines that can be tested for mixing ability using "traitblind" approaches.

\subsubsection{Trait-based selection}

The general idea here is to select independently sets of varieties for sets of trait combinations that have been shown to be favorable in mixtures because they foster complementarity and sampling effects (Fig. 3d). This could (1) enhance sampling and complementarity effects in mixtures of already existing varieties through the amplification of betweenvariety variability in some traits and (2) create new sampling and complementarity effects through the creation of betweenvariety variability for traits that are rather homogeneous with conventional breeding. In such "trait-based" approach, key traits have been identified and trait combinations that maximize variety mixture performances have been defined (see Section 3). Such traits can be involved in limiting 
aggressiveness regarding neighboring plants (e.g., average plant height, erected leaves...) or in the efficient uptake of particular nutrients. An example of complementary between trait values is given by the case of resistance to pathogen, where an infrequent specific resistance can contribute to GMA (Knott and Mundt 1990). The breeding methodology will then rely on the usual and powerful breeding schemes: (1) identification of the best parents to cross, (2) generation of set of recombinant lines (through selfing plants in bulk or in single seed descent, or through double haploidization), (3) selection of lines with maximized values on targeted traits in these progenies observed in pure stand. Depending on the complexity of the trait-based mixture design $(3,4$ or more specific ideotypes to select in parallel), a same cross will be eventually used to derive different ideotypes. As discussed above, the specific performance of a mixture should come both from the heterogeneity of its components for some traits (breeding for variance) (Litrico and Violle 2015) and from the homogeneity of its components for other traits.

\subsubsection{Trait-blind selection for mixing ability}

Taking into account the ability to grow in mixture in early generation selection (i.e., two or three generations of selfing after crossing) requires designing trials allowing the prediction of the mixing ability for a large series ( $n$, usually several hundreds) of inbred families using small amounts of seeds for each entry, without growing all possible mixtures $(n(n-1) / 2)$. Two main strategies can be considered depending on the relative importance of GMA vs SMA (see Section 3).

If GMA is large compared to SMA (such as in Gallandt et al. 2001), the most efficient approach would be to find good predictors of the (general) ability to grow in heterogeneous stands for a given genotype and screen the set of entries based on this basis. Predicting GMA in a "trait-blind" approach would consist in assessing the average mixing ability of a genotype when exposed to a small selected subset of genotypes, called "testers" (borrowed from hybrid breeding), that would be representative of a large range of possible phenotypes. For example, $n$ varieties could be tested against three to five testers ( $3 n$ to $5 n$ tests of binary mixtures). The efficiency of prediction strongly depends on the chosen testers. An alternative design is to grow the $n$ varieties to be tested in singlerow plots (i.e., very small plots that are often used in early generation breeding when few seeds are available for each entry) where different randomly chosen genotypes are sown in adjacent plots (Dawson and Goldringer 2012). Each entry is therefore submitted to interactions with two different genotypes. Three to five replications would provide $2 \times 3$ to $2 \times 5$ random interactions with different neighbors for each tested family. It has been shown that strong between-plot competition occurs within this design, which can be modeled in terms of neighbor effects (Besag and Kempton 1986;
Foucteau et al. 2000; Goldringer et al. 1994; Kempton 1982). The producer-competitor model (Foucteau et al. 2000; Kempton 1985) proved to be efficient in accounting for interactions between genotypes of adjacent plots by allowing the estimation of the producer and the competitor effects of each genotype. Looking for genotypes with a high producer effect (high level of production under competition conditions) and with a high competitor effect (beneficial effects on neighbors) could allow selection for the GMA of these genotypes (Dawson and Goldringer 2012). Although the correlation between producer and competitor effects of genotypes tended to be negative in the study of Foucteau et al. (2000), several of the 40 studied bread wheat genotypes showed both moderate to high producer and competitor effects, thus indicating possibilities for breeding. If SMA is of the same order of magnitude than GMA (Knott and Mundt 1990), complementarity among varieties has to be assessed extensively, which requires complex blending schemes and large and expensive field experiments.

\subsubsection{Combining trait-blind and trait-based selection}

Combination of trait-blind and trait-based approaches could allow for a better selection for both GMA and SMA. In the "trait-based" approach, key traits can be identified and trait combinations that maximize mixture performances can be defined (see Section 3). Then, the large set of early generation families can be screened in pure stands for these traits. This allows the identification of a short-list of mixtures with appropriate combinations of trait values to be tested in field. In the "trait-blind" approach, SMA could be selected for by identifying or defining complementary groups for mixing ability. Note that in such schemes, genotypes would be selected both on GMA and SMA. In hybrid breeding, groups of genotypes providing a good hybrid value when crossed among groups and a poor value when crossed within groups (heterotic groups) may pre-exist. Specific breeding schemes such as reciprocal recurrent selection can be designed to improve both general and specific combining ability by increasing complementarity among these groups (Comstock et al. 1949). Complementary groups for mixing ability could be initially defined on the basis of the complementarity of the traits identified in the "trait-based" approach or of the genetic structure of the diversity of the populations studied and reciprocal recurrent selection for mixing ability could be carried out. Yet, the issue of selecting for good mixtures of $n$ varieties would make the scheme more complex and hypothetical with possibly more than two compatibility groups to handle. Furthermore, multiple ecosystem services would also need to be integrated in the scheme as they are elements of the mixing value.

Traits of varieties are plastic and likely differ between varieties grown in mixtures and in single variety stands. This 
shows that some mechanisms we are seeking to foster (i.e., complementarity effects) can only be observed in mixtures. This is a limitation of the trait approach and emphasizes that breeding for mixtures will also require assessing directly the "mixture phenotype" of mixtures, at least on a relevant number of mixtures, in order to better understand and predict the effect of trait diversity on services. A response to this issue and an alternative to these breeding strategies could be to select within highly diverse populations grown over time in contrasted farming conditions, as suggested by Finckh (2008). Allard and Adams (1969) found that an increase in yield of all components of a mixture when grown in a mixture compared to when grown separately in pure lines (ecological combining ability) was rare in mixtures formed by varieties selected as pure lines but common in mixtures of barley lines that had been cultivated together for many generations (Dawson and Goldringer 2012). This is consistent with grassland experiments, in which species grown in mixtures tend to evolve contrasting trait values, thereby increasing biodiversity effects through stronger complementarity effects (ZuppingerDingley et al. 2014).

Finally, all these breeding schemes require original experimental designs to test for the mixing ability and relevant sets of traits, but are based on inbred-lines development, and can therefore directly benefit from both marker-assisted selection and genomic selection. The recent developments in genomics should allow identifying the genomic areas that maximize positive interactions between genotypes, in a similar way to the hybrid breeding schemes ( $\mathrm{Xu}$ et al. 2014; Zhang et al. 2015). Both trait-based and trait-blind approaches can be considered as « gene-blind », i.e., only based on phenotypes. This means that beyond the trait approach, the development of knowledge on the relations between genes of single varieties and their traits, and ultimately between a "mixture genotype" and a "mixture phenotype" will be required to select new varieties for mixtures. In this way, genetic engineering could ultimately be useful to precisely target the genes required for mixtures (Zeller et al. 2012). This would be useful at least in the absence of appropriate trait combination in existing varieties and in case of strong linkage disequilibrium.

\section{Conclusion and perspectives}

Results on the consequences of genetic diversity on communities and ecosystems are now accumulating either in natural/ experimental ecosystems (Crawford et al. 2012; Crutsinger et al. 2006; Hughes et al. 2008) or in agricultural systems (Chateil et al. 2013; Hajjar et al. 2008; Kiær et al. 2009; Kiær et al. 2012; Tooker et al. 2012; Zeller et al. 2012), and our first conclusion is that it would be particularly interesting to develop mixtures of varieties for a multifunctional lowinput agriculture and that selecting specifically new varieties for mixtures would highly increase the performance of mixtures. These conclusions have been already reached for intercropping (Brooker et al. 2015). However, many steps are still required to develop mixtures of varieties on a wide scale. These steps involve breaking through cultural, technical, and organizational barriers. They also involve implementing new researches to bridge diverse knowledge gaps that are listed below, and revisiting some agronomic and socio-economic dogma for exploring what could be efficient agricultural practices in a changing world characterized by increasingly scarce energy, water, and nutrient resources. We sum up below our recommendations in terms of research needs.

The mechanisms behind the effects of mixtures of varieties have so far not been systematically studied or disentangled in detailed case studies (Hughes et al. 2008). In particular, the relative influence of complementarity and sampling effects has hardly been assessed (but see Drummond and Vellend 2012; Schöb et al. 2015). For example, a meta-analysis of 246 experiments on wheat and barley (Kiær et al. 2009) found a mean positive effect of mixtures on yield of $2.7 \%$ but gives few hints on the mechanisms behind this effect. Specific experiments are needed to document the precise ecological mechanisms behind complementary and sampling effects. Experiments are needed to analyze the possible interactions between varieties and their outcome for other organisms (soil microorganisms and fauna, pathogens and pests, aboveground organisms, weeds). Other experiments are needed to test how differences in aboveground and belowground traits may change crop efficiency to capture resources (nutrients, water, and light). Importantly, there are so far very few results on the impact of mixtures of varieties on the provision of ecosystem services beyond grain yield and the underlying mechanisms. Indeed, both complementarity and sampling effects have initially been studied for their potential capacity to increase the production of plant biomass and not for their impact on ecosystem services.

We lack large experiments manipulating the intra-field number of varieties in the same way as species richness and functional diversity have been manipulated (Hector et al. 1999; Roscher et al. 2008; Tilman et al. 1997). This would require the implementation of many mixtures of varieties choosing varieties within a large and functionally diverse pool of varieties. These experiments should manipulate the number of varieties within each mixture, the traits of these varieties and the diversity of their traits. Such experiments would also require monitoring comprehensively the consequences in terms of yield, yield stability, and other ecosystem services. In this perspective, a difficulty is that fully assessing the influence of selection and complementarity effects requires measuring the biomass of each variety within a mixture (Loreau and Hector 2001), which is much more difficult than measuring the biomass of each species in a community. 
Studying the effects of mixtures of varieties involves many interacting degrees of complexity: interactions between different genotypes (GXG), environmental temporal and spatial variability $(\mathrm{E})$ and agricultural practices $(\mathrm{M})$. An alternative to deal with this complexity (GXGXEXM) is to rely on participatory approaches, where decentralized experiments under the expertise of farmers/extension services/technical advisors can participate to a large collaborative network. Such in situ empirical studies can be a very efficient method to explore the multi-dimensional GxGxExM space. This would allow assessing the long-term effect of mixtures at the farm scale, which is critical because some effects of mixtures of varieties, e.g., on soil biodiversity and soil carbon and mineral stocks, are probably only detectable on the long-term (more than a decade) and at large scales (either at the field or landscape scale and not at the scale of small experimental plots).

Farmers need rules to design variety mixtures and crop breeders need new methods to select varieties for mixtures. To do so, we have described a trait-based approach and a trait-blind approach. The two approaches are potentially powerful and have their own virtues. Indeed, traitbased and trait-blind approaches are complementary, the former being more mechanistic and the latter being more statistic. The trait-blind breeding is expected to strongly impact the traits responsible for the mixing ability, as already shown for classical breeding, most of which is trait-blind. Nevertheless, the trait approach and the knowledge of the underlying ecological mechanism seem particularly promising on the long run. We suggest that rules to design mixtures could be based on the knowledge of variety functional traits and that the rules could be based on combinations of trait values. However, nearly all the necessary work to design such rules remains to be achieved and the first step would be to build the necessary trait databases for crops (Martin et al. 2015) and to describe the links between crop traits and ecosystem services. While the conceptual framework developed in ecology to analyze the effects of species richness is very helpful to predict the kind of ecological mechanisms that could make mixtures efficient, we need to develop a new framework to guide the choice of varieties to be mixed. Moreover, while the original ecological theories linking biodiversity and ecosystem functioning hardly has any evolutionary component, the breeding of new varieties is clearly a crucial component of this desired framework that will have to combine positive ecological interactions between varieties and the way to foster these interactions through breeding.

Acknowledgments The authors acknowledge support from the ANR through the project Wheatamix and from the INRA meta-programme EcoServ through the project SolFaMi. We thank the anonymous reviewers who have helped to improve the article.

\section{References}

Aanderud Z, Bledsoe CS (2009) Preference for ${ }^{15} \mathrm{~N}$-ammonium, ${ }^{15} \mathrm{~N}$ nitrate, and ${ }^{15} \mathrm{~N}$-glycine differ among dominant exotic and subordinate native grasses from a California oak woodland. Env Exp Bot 65:205-209

Abakumova M, Zobel K, Lepik A, Semchenko M (2016) Plasticity in plant functional traits is shaped by variability in neighbourhood species composition. New Phytol 211(2):455-463. doi:10.1111/nph.13935

Allan E, Weisser WW, Fischer M, Schulze ED, Weigelt A et al (2013) A comparison of the strength of biodiversity effects across multiple functions. Oecologia 173(1):223-237. doi:10.1007/s00442-0122589-0

Allard RW, Adams J (1969) Population studies in predominantly selfpollinating species. XIII. Intergenotypic competition and population structure in barley and wheat. Am Nat 103:621-645

Altieri MA (1989) Agroecology — a new research and development paradigm for world agriculture. Agriculture Ecos Envir 27(1-4):37-46. doi:10.1016/0167-8809(89)90070-4

Altieri MA (1999) The ecological role of biodiversity in agroecosystems. Agri Ecos Env 74(1-3):19-31. doi:10.1016/S0167-8809(99)00028-6

Barot S, Lata J-C, Lacroix G (2012) Meeting the relational challenge of ecological engineering. Ecol Eng 45:13-23. doi:10.1016/j.ecoleng. 2011.04.006

Bavec F, Bavec M (2001) Chlorophyll meter readings of winter wheat cultivars and grain yield prediction. Commun Soil Sci Plan 32: 2709-2719. doi:10.1081/CSS-120000956

de Bello F, Lavorel S, Diaz S, Harrington R, Cornelissen JHC et al (2010) Towards an assessment of multiple ecosystem processes and services via functional traits. Biodi Cons 19(10):2873-2893. doi:10. 1007/s10531-010-9850-9

Bertness MD, Callaway R (1994) Positive interactions in communities. Tree 9:191-193. doi:10.1016/0169-5347(94)90088-4

Besag JE, Kempton RA (1986) Statistical analysis of field experiments using neighboring plots. Biometrics 42:231-251. doi:10.2307/ 2531047

Bessler H, Temperton VM, Roscher C, Buchmann N, Schmid B et al (2009) Aboveground overyielding in grassland mixtures is associated with reduced biomass partitioning to belowground organs. Ecology 90(6):1520-1530. doi:10.1890/08-0867.1

Bøckman OC (1997) Fertilizers and biological nitrogen fixation as sources of plant nutrients: perspectives for future agriculture. Plant Soil 194:11-14. doi:10.1023/A:1004212306598

Bonnin I, Bonneuil C, Goffaux R, Montalent P, Goldringer I (2014) Explaining the decrease in the genetic diversity of wheat in France over the 20th century. Agri Ecos Envir 195:183-192. doi:10.1016/j. agee.2014.06.003

Boudsocq S, Lata JC, Mathieu J, Abbadie L, Barot S (2009) Modelling approach to analyze the effects of nitrification inhibition on primary production. Func Ecol 23:220-230. doi:10.1111/j.1365-2435.2008. 01476.x

Brisson N, Gate P, Gouache D, Charmet G, Oury F-X et al (2010) Why are wheat yields stagnating in Europe? A comprehensive data analysis for France. Field Crops Res 119(1):201-212. doi:10.1016/j.fcr. 2010.07.012

Brooker RW, Bennett AE, Cong W-F, Daniell TJ, George TS et al (2015) Improving intercropping: a synthesis of research in agronomy, plant physiology and ecology. New Phytol 206(1):107-117. doi:10.1111/ nph. 13132

Burns JH, Strauss SY (2012) Effects of competition on phylogenetic signal and phenotypic plasticity in plant functional traits. Ecology 93:S126-S137

Callaway RM, Brooker RW, Choler P, Kikvidze Z, Lortie CJ et al (2002) Positive interactions among alpine plants increase with stress. Nature 417(6891):840-847. doi:10.1038/nature00805 
Campbell BD, Grime JP, Mackey JML (1991) A trade-off between scale and precision in resource foraging. Oecologia 87:532-538. doi:10. 1007/BF00320417

Cantarel AA, Pommier T, Desclos-Theveniau M, Diquélou S, Dumont M et al (2015) Using plant traits to explain plant-microbe relationships involved in nitrogen acquisition. Ecology 96:788-799. doi:10.1890/ 13-2107.1

Cardinale BJ, Palmer MA, Collins SL (2003) Species diversity enhances ecosystem functioning through interspecific facilitation. Nature 415: 426-429. doi:10.1038/415426a

Chateil C, Goldringer I, Tarallo L, Kerbiriou C, Le Viol I et al (2013) Crop genetic diversity benefits farmland biodiversity in cultivated fields. Agri Ecosys Envir 171:25-32. doi:10.1016/j.agee.2013.03. 004

Cianciaruso MV, Batalha MA, Gaston KJ, Petchey OL (2009) Including intraspecific variability in functional diversity. Ecology 90(1):8189. doi:10.1890/07-1864.1

Comstock RE, Robinson HF, Harvey PH (1949) A breeding procedure designed to make maximum use of both general and specific combining ability. Agro J 41:360-367

Cook-Patton SC, McArt SH, Parachnowitsch AL, Thaler JS, Agrawal AA (2011) A direct comparison of the consequences of plant genotypic and species diversity on communities and ecosystem function. Ecology 92(4):915-923. doi:10.1890/10-0999.1

Cordell D, Drangert JO, White S (2009) The story of phosphorus: global food security and food for thought. Global Env Change 19(2):292305. doi:10.1016/j.gloenvcha.2008.10.009

Cornelissen JHC, Lavorel S, Garnier E, Díaz S, Buchmann N et al (2003) A handbook of protocols for standardised and easy measurement of plant functional traits worldwide. Aus J Bot 51:335-380. doi:10. 1071/BT02124

Crawford KM, Rudgers JA, Cahill J (2012) Plant species diversity and genetic diversity within a dominant species interactively affect plant community biomass. J Ecol 100(6):1512-1521. doi:10.1111/j.13652745.2012.02016.x

Crutsinger GM, Collins MD, Fordyce JA, Gompert Z, Nice CC et al (2006) Plant genotypic diversity predicts community structure and governs an ecosystem process. Science 313(5789):966-968. doi:10. 1126/science. 1128326

Dawson JC, Goldringer I (2012) Breeding for genetically diverse populations: variety mixtures and evolutionary populations. In: van Bueren ETL, Myers JR (eds) Organic crop breeding. WileyBlackwell, pp 77-98. doi:10.1002/9781119945932.ch5

Debaeke P, Rouet P, Justes E (2006) Relationship between the normalized SPAD index and the nitrogen nutrition index: application to durum wheat. J Plant Nutr 29:75-92. doi:10.1080/01904160500416471

Debaeke P, Gauffreteau A, Durel C-E, Jeuffroy M-H (2014) Conception d'idéotypes variétaux en réponse aux nouveaux contextes agricoles et environnementaux. Agro Envir Soc 4:65-73

Díaz S, Cabido M (2001) Vive la différence: plant functional diversity matters to ecosystem process. Trends Ecol Evol 16(11):646-655. doi:10.1016/S0169-5347(01)02283-2

Dornbusch T, Baccar R, Watt J, Hillier J, Bertheloot J et al (2011) Plasticity of winter wheat modulated by sowing date, plant population density and nitrogen fertilisation: dimensions and size of leaf blades, sheaths and internodes in relation to their position on a stem. Field Crops Res 121(1):116-124. doi:10.1016/j.fcr.2010.12.004

Drummond EB, Vellend M (2012) Genotypic diversity effects on the performance of Taraxacum officinale populations increase with time and environmental favorability. PLoS One 7(2):e30314. doi:10. 1371/journal.pone.0030314

Ecarnot M, Compan F, Roumet P (2013) Assessing leaf nitrogen content and leaf mass per unit area of wheat in the field throughout plant cycle with a portable spectrometer. Field Crop Res 140:44-50. doi: 10.1016/j.fcr.2012.10.013
Eggermont H, Balian E, Azevedo J, Beumer V, Brodin T et al (2015) Nature-based solutions: new influence for environmental management and research in Europe. Gaia 24:243-248. doi:10.14512/gaia. 24.4 .9

FAO (2010) The second report on the state of the world's plant genetic resources for food and agriculture. FAO, Rome

Finckh MR (2008) Integration of breeding and technology into diversification strategies for disease control in modern agriculture. Eur J Plant Path 121(3):399-409. doi:10.1007/s10658-008-9273-6

Finckh MR, Mundt CC (1992) Stripe rust, yield, and plant competition in wheat cultivar mixtures. Phytopathology 82:905-913

Finckh MR, Gacek ES, Goyeau H, Lannou C, Merz U et al (2000) Cereal variety and species mixtures in practice, with emphasis on disease resistance. Agronomie 20:813-837. doi:10.1051/agro:2000177

Foley JA, Ramankutty N, Brauman KA, Cassidy ES, Gerber JS et al (2011) Solutions for a cultivated planet. Nature 478(7369):337342. doi:10.1038/nature 10452

Fornara DA, Tilman D (2009) Ecological mechanisms associated with the positive diversity-productivity relationship in an N-limited grassland. Ecology 90(2):408-418. doi:10.1890/08-0325.1

Foucteau V, Brabant P, Monod H, David O, Goldringer I (2000) Correction models for intergenotypic competition in winter wheat. Agronomie 20:943-995. doi:10.1051/agro:2000170

Fridley JD, Grime JP (2010) Community and ecosystem effects of intraspecific genetic diversity in grassland microcosms of varying species diversity. Ecology 91(8):2272-2283

Gaba S, Lescourret F, Boudsocq S, Enjalbert J, Hinsinger P et al (2015) Multiple cropping systems as drivers for providing multiple ecosystem services: from concepts to design. Agro Sust Dev 35(2):607623. doi:10.1007/s13593-014-0272-z

Gallandt ER, Dofing SM, Reisenauer PE, Donaldson E (2001) Diallel analysis of cultivar mixtures in winter wheat. Crop Sci 41:792-796. doi:10.2135/cropsci2001.413792x

Gamfeldt L, Snall T, Bagchi R, Jonsson M, Gustafsson L et al (2013) Higher levels of multiple ecosystem services are found in forests with more tree species. Nat Comm 4:1340. doi:10.1038/ ncomms 2328

Garcia-Palacios P, Maestre FT, Gallardo A (2011) Soil nutrient heterogeneity modulates ecosystem responses to changes in the identity and richness of plant functional groups. J Ecol 99(2):551-562. doi:10. $1111 / j .1365-2745.2010 .01765 . x$

Gizlice Z, Carter TE, Burton JW, Emigh TH (1989) Partitioning of blending ability using two-way blends and component lines of soybean. Crop Sci 29:885-889

Goldringer I, Brabant P, Kempton RA (1994) Adjustment for competition between genotypes in single-row-plot trials of winter wheat (Triticum aestivum). Plant Breed 112:294-300. doi:10.1111/j. 1439-0523.1994.tb00687.x

Griffing B (1956) Concept of general and specific combining ability in relation to diallel crossing systems. Austr J Biol Sci 9:463-493. doi: 10.1071/BI9560463

Grime JP, Cornelissen JHC, Thompson K, Hodgson JG (1996) Evidence of a causal connection between anti-herbivore defence and the decomposition rate of leaves. Oikos 77:489-494. doi:10.2307/ 3545938

Gross K, Cardinale BJ, Fox JW, Gonzalez A, Loreau M et al (2014) Species richness and the temporal stability of biomass production: a new analysis of recent biodiversity experiments. Am Nat 183:112. doi: $10.1086 / 673915$

Hajjar R, Jarvis DI, Gemmill-Herren B (2008) The utility of crop genetic diversity in maintaining ecosystem services. Agri Ecosys Envir 123(4):261-270. doi:10.1016/j.agee.2007.08.003

Hauggaard-Nielsen H, Jensen ES (2005) Facilitative root interactions in intercrops. Plant Soil 274(1-2):237-250. doi:10.1007/s11104-004$1305-1$ 
Hautier Y, Seabloom EW, Borer ET, Adler PB, Harpole WS et al (2014) Eutrophication weakens stabilizing effects of diversity in natural grasslands. Nature 508:521-525. doi:10.1038/nature13014

He J-S, Bazzaz FA, Schmid B (2002) Interactive effects of diversity, nutrients and elevated $\mathrm{CO}_{2}$ on experimental plant communities. Oikos 97:337-348

Hector A, Bagchi R (2007) Biodiversity and ecosystem multifunctionality. Nature 448(7150):188-190. doi:10.1038/ nature 05947

Hector A, Schmid B, Beierkuhnlein C, Caldeira MC, Diemer M et al (1999) Plant diversity and productivity experiments in European grasslands. Science 286:1123-1126. doi:10.1126/science.286. 5442.1123

Hector A, Joshi J, Scherer-Lorenzen M, Schmid B, Spehn EM et al (2007) Biodiversity and ecosystem functioning: reconciling the results of experimental and observational studies. Func Ecol 21(5): 998-1002. doi:10.1111/j.1365-2435.2007.01308.x

Hector A, Hautier Y, Saner P, Wacker L, Bagchi R et al (2010) General stabilizing effects of plant diversity on grassland productivity through population asynchrony and overyielding. Ecology 91(8): 2213-2220. doi:10.1890/09-1162.1

Herms DA, Mattson WJ (1992) The dilemma of plants: to grow or defend. Quat Rev Biol 67(3):283-335

Hetrick BAD, Wilson GWT, Cox TS (1992) Mycorrhizal dependence of modern wheat varieties, landraces, and ancestrors. Can J Bot 70: 2032-2040. doi:10.1139/b92-253

Hinsinger P (2001) Bioavailability of soil inorganic P in the rhizosphere as affected by root-induced chemical changes: a review. Plant Soil 237:173-195. doi:10.1023/A:1013351617532

Holmgren M, Scheffer M (2010) Strong facilitation in mild environments: the stress gradient hypothesis revisited. J Ecol 98(6):12691275. doi:10.1111/j.1365-2745.2010.01709.x

Howden SM, Soussana JF, Tubiello FN, Chhetri N, Dunlop M et al (2007) Adapting agriculture to climate change. Proc Natl Acad Sci U S A 104(50):19691-19696. doi:10.1073/pnas.0701890104

Hughes AR, Stachowicz JJ (2004) Genetic diversity enhances the resistance of a seagrass ecosystem to disturbance. Proc Natl Acad Sci U S A 101(24):8998-9002. doi:10.1073/pnas.0402642101

Hughes AR, Inouye BD, Johnson MTJ, Underwood N, Vellend M (2008) Ecological consequences of genetic diversity. Ecolog Lett 11(6): 609-623. doi:10.1111/j.1461-0248.2008.01179.x

IPCC (2013) Climate change 2013: the physical science basis. Contribution of working group I to the fifth assessment report of the intergovernmental panel on climate change. Cambridge University Press, Cambridge, United Kingdom and New York, NY, USA

Isbell F, Calcagno V, Hector A, Connolly J, Harpole WS et al (2011) High plant diversity is needed to maintain ecosystem services. Nature 477(7363):199-202. doi:10.1038/nature10282

Jarvis DI, Brown AH, Cuong PH, Collado-Panduro L, LatournerieMoreno L et al (2008) A global perspective of the richness and evenness of traditional crop-variety diversity maintained by farming communities. Proc Natl Acad Sci U S A 105(14):5326-5331. doi: 10.1073/pnas.0800607105

Jiang L, Pu Z, Nemergut DR (2008) On the importance of the negative selection effect for the relationship between biodiversity and ecosystem functioning. Oikos 117:488-493. doi:10.1111/j.2007.00301299.16401.x

Johnson MTJ, Lajeunesse MJ, Agrawal AA (2006) Additive and interactive effects of plant genotypic diversity on arthropod communities and plant fitness. Ecol Lett 9(1):24-34. doi:10.1111/j.1461-0248. 2005.00833.x

Kattge J, Diaz S, Lavorel S, Prentice IC, Leadley P et al (2011) TRY - a global database of plant traits. Global Chan Biol 17(9):2905-2935. doi:10.1111/j.1365-2486.2011.02451.x
Kempton RA (1982) Adjustment for competition between varieties in plant breeding trials. J Agri Sci 98:599-611. doi:10.1017/ S0021859600054381

Kempton RA (1985) Statistical models for interplot competition. Asp Appl Biol 10:110-120

Kiær LP, Skovgaard IM, Østergård H (2009) Grain yield increase in cereal variety mixtures: a meta-analysis of field trials. Field Crops Res 114(3):361-373. doi:10.1016/j.fcr.2009.09.006

Kiær LP, Skovgaard IM, Østergård H (2012) Effects of inter-varietal diversity, biotic stresses and environmental productivity on grain yield of spring barley variety mixtures. Euphytica 185(1):123-138. doi:10.1007/s10681-012-0640-1

Knott EA, Mundt CC (1990) Mixing ability analysis of wheat cultivar mixtures under diseased and nondiseased conditions. Theoret Appl Gen 80:313-320. doi:10.1007/BF00210065

Kotowska AM, Cahill JF, Keddie BA (2010) Plant genetic diversity yields increased plant productivity and herbivore performance. $\mathrm{J}$ Ecol 98(1):237-245. doi:10.1111/j.1365-2745.2009.01606.x

Lata J-C, Degrange V, Raynaud X, Maron P-A, Lensi R et al (2004) Grass populations control nitrification in savanna soils. Funct Ecol 18: 605-611. doi:10.1111/j.0269-8463.2004.00880.x

Latz E, Eisenhauer N, Rall BC, Allan E, Roscher C et al (2012) Plant diversity improves protection against soil-borne pathogens by fostering antagonistic bacterial communities. J Ecol 100(3):597-604. doi:10.1111/j.1365-2745.2011.01940.x

Laughlin DC (2011) Nitrification is linked to dominant leaf traits rather than functional diversity. J Ecol 99(5):1091-1099. doi:10.1111/j. 1365-2745.2011.01856.x

Lavorel S, Garnier E (2002) Predicting changes in community composition and ecosystem functioning from plant traits: revisiting the Holy Grail. Func Ecol 16:545-556. doi:10.1046/j.1365-2435.2002. 00664.x

Le Roux X, Schmid B, Poly F, Barnard RL, Niklaus PA et al (2013) Soil environmental conditions and microbial build-up mediate the effect of plant diversity on soil nitrifying and denitrifying enzyme activities in temperate grasslands. PLoS One 8(4):e61069. doi:10.1371/ journal.pone. 0061069

Leff B (2004) Geographic distribution of major crops across the world. Glob Biogeo Cycles 18(1). doi:10.1029/2003gb002108

Li L, Li S-M, Sun J-H, Bao X-G, Zhang H-G et al (2007) Diversity enhances agricultural productivity via rhizosphere phosphorus facilitation on phosphorus-deficient soils. Proc Natl Acad Sci U S A 104: 11192-11196. doi:10.1073/pnas.0704591104

Li L, Tilman D, Lambers H, Zhang F-S (2014) Plant diversity and overyielding: insights from belowground facilitation of intercropping in agriculture. New Phytol 203(1):63-69. doi:10. $1111 / \mathrm{nph} .12778$

Litrico I, Violle C (2015) Diversity in plant breeding: a new conceptual framework. Trends Plant Sci 20(10):604-613. doi:10.1016/j.tplants. 2015.07.007

Loeuille N, Barot S, Georgelin E, Kylafis G, Lavigne C (2013) Ecoevolutionary dynamics of agricultural networks: implications for a sustainable management. Adv Ecol Res 49:339-435. doi:10.1016/ B978-0-12-420002-9.00006-8

Lopez CG, Mundt CC (2000) Using mixing ability analysis from twoway cultivar mixtures to predict the performance of cultivars in complex mixtures. Field Crops Res 68:121-132. doi:10.1016/ S0378-4290(00)00114-3

Loreau M (1998) Separating sampling and other effects in biodiversity experiments. Oikos 82(3):600-602

Loreau M (2000) Biodiversity and ecosystem functioning: recent theoretical advances. Oikos 91:3-17. doi:10.1034/j.1600-0706.2000. 910101.x

Loreau M (2004) Does functional redundancy exist? Oikos 104(3):606611. doi:10.1111/j.0030-1299.2004.12685.x 
Loreau M, Hector A (2001) Partitioning selection and complementarity in biodiversity experiments. Nature 412:72-76. doi:10.1038/ 35083573

Lynch JP, Brown KM (2012) New roots for agriculture: exploiting the root phenome. Philos Trans Royal Soc Lond B 367(1595):15981604. doi: $10.1098 /$ rstb. 2011.0243

Maestre FT, Callaway RM, Valladares F, Lortie CJ (2009) Refining the stress-gradient hypothesis for competition and facilitation in plant communities. J Ecol 97(2):199-205. doi:10.1111/j.1365-2745.2008. 01476.x

Malézieux E (2011) Designing cropping systems from nature. Agro Sustain Develop 32(1):15-29. doi:10.1007/s13593-011-0027-z

Marquard E, Weigelt A, Roscher C, Gubsch M, Lipowsky A et al (2009) Positive biodiversity-productivity relationship due to increased plant density. J Ecol 97(4):696-704. doi:10.1111/j.1365-2745.2009. 01521.x

Martin AR, Isaac ME, Manning P (2015) Plant functional traits in agroecosystems: a blueprint for research. J Appl Ecol 52(6):14251435. doi:10.1111/1365-2664.12526

de Miranda-Filho JB, Chaves LJ (1991) Procedures for selecting composites based on prediction methods. Theoret Appl Genetics 81: 265-271. doi:10.1007/BF00215732

Mouchet MA, Villéger S, Mason NWH, Mouillot D (2010) Functional diversity measures: an overview of their redundancy and their ability to discriminate community assembly rules. Func Ecol 24(4):867876. doi:10.1111/j.1365-2435.2010.01695.x

Murphy KM, Campbell KG, Lyon SR, Jones SS (2007) Evidence of varietal adaptation to organic farming systems. Field Crops Res 102:172-177. doi:10.1016/j.fcr.2007.03.011

Nakhforoosh A, Grausgruber H, Kaul H-P, Bodner G (2014) Wheat root diversity and root functional characterization. Plant Soil 380(1-2): 211-229. doi:10.1007/s11104-014-2082-0

Newton AC, Swanston JS, Guy DC, Ellis RP (1998) The effect of cultivar mixtures on malting quality in winter and spring barley. J Inst Brew 104:41-45. doi:10.1002/j.2050-0416.1998.tb00973.x

Østergård H, Finckh MR, Fontaine L, Goldringer I, Hoad SP et al (2009) Time for a shift in crop production: embracing complexity through diversity at all levels. J Sci Food Agric 89:1439-1445. doi:10.1002/ jsfa.3615

Palma J, Graves AR, Burgess PJ, van der Werf W, Herzog F (2007) Integrating environmental and economic performance to assess modern silvoarable agroforestry in Europe. Ecol Econ 63(4):759767. doi:10.1016/j.ecolecon.2007.01.011

Parker JD, Salminen JP, Agrawal AA (2010) Herbivory enhances positive effects of plant genotypic diversity. Ecol Lett 13(5):553-563. doi: 10.1111/j.1461-0248.2010.01452.x

Pérez-Harguindeguy N, Díaz S, Garnier E, Lavorel S, Poorter H et al (2013) New handbook for standardised measurement of plant functional traits worldwide. Aus J Bot 61(3):167. doi:10.1071/bt12225

Postma JA, Lynch JP (2012) Complementarity in root architecture for nutrient uptake in ancient maize/bean and maize/bean/squash polycultures. Ann Bot 110(2):521-534. doi:10.1093/aob/mcs082

del Pozo A, Matus I, Serret MD, Araus JL (2014) Agronomic and physiological traits associated with breeding advances of wheat under high-productive Mediterranean conditions. The case of Chile. Envir Exp Bot 103:180-189. doi:10.1016/j.envexpbot.2013.09.016

Prieto I, Violle C, Barre P, Durand J-L, Ghesquiere M et al (2015) Complementary effects of species and genetic diversity on productivity and stability of sown grasslands. Nature Plants. doi:10.1038/ nplants. 2015.33

Quetier F, Lavorel S, Thuiller W, Davies I (2007) Plant-trait-based modeling assessment of ecosystem-service sensitivity to land-use change. Ecol Appl 17(8):2377-2386

Reich PB, Knops J, Tilman D, Craine J, Ellsworth D et al (2001) Plant diversity enhances ecosystem responses to elevated $\mathrm{CO}_{2}$ and nitrogen deposition. Nature 410:809-812
Reich PB, Tilman D, Naeem S, Ellsworth DS, Knops J et al (2004) Species and functional group diversity independently influence biomass accumulation and its response to $\mathrm{CO}_{2}$ and N. Proc Natl Acad Sci U S A 101(27):10101-10106. doi:10.1073/pnas.0306602101

Renting H, Rossing WA, Groot JC, Van der Ploeg JD, Laurent C et al (2009) Exploring multifunctional agriculture. A review of conceptual approaches and prospects for an integrative transitional framework. J Environ Manag 90(Suppl 2):S112-S123. doi:10.1016/j. jenvman.2008.11.014

Richards RA (2000) Selectable traits to increase crop photosynthesis and yield of grain crops. J Exp Bot 51:447-458. doi:10.1093/jexbot/51. suppl_1.447

de Roman M, Fernandez I, Wyatt T, Sahrawy M, Heil M et al (2011) Elicitation of foliar resistance mechanisms transiently impairs root association with arbuscular mycorrhizal fungi. J Ecol 99(1):36-45. doi:10.1111/j.1365-2745.2010.01752.x

Roscher C, Thein S, Schmid B, Scherer-Lorenzen M (2008) Complementary nitrogen use among potentially dominant species in a biodiversity experiment varies between two years. J Ecol 96(3): 477-488. doi:10.1111/j.1365-2745.2008.01353.x

Sarandon SJ, Sarandon R (1995) Mixture of cultivars: pilot field trial of an ecological alternative to improve production or quality of wheat (Triticum aestivum). J Appl Ecol 32:288-294. doi:10.2307/2405096

Scherber C, Eisenhauer N, Weisser WW, Schmid B, Voigt W et al (2010) Bottom-up effects of plant diversity on multitrophic interactions in a biodiversity experiment. Nature 468(7323):553-556. doi:10.1038/ nature09492

Scherer-Lorenzen M, Palmborg C, Prinz A, Schulze E-D (2003) The role of plant diversity and composition for nitrate leaching in grasslands. Ecology 84(6):1539-1552. doi:10.1890/0012-9658(2003) 084[1539:TROPDA]2.0.CO;2

Schöb C, Kerle S, Karley AJ, Morcillo L, Pakeman RJ et al (2015) Intraspecific genetic diversity and composition modify specieslevel diversity-productivity relationships. New Phytol 205:720 730. doi:10.1111/nph.13043

Schweitzer JA, Bailey JK, Hart SC, Whitham TG (2005) Nonadditive effects of mixing cottonwood genotypes on litter decomposition and nutrient dynamics. Ecology 86:2834-2840. doi:10.1890/04-1955

Schweitzer JA, Bailey JK, Fischer DG, LeRoy CJ, Lonsdorf EV et al (2008) Plant-soil-microorganism interactions: heritable relationship between plant genotype and associated soil microorganisms. Ecology 89(3):773-781. doi:10.1890/07-0337.1

Shahzad T, Chenu C, Genet P, Barot S, Perveen N et al (2015) Contribution of exudates, arbuscular mycorrhizal fungi and litter depositions to the rhizosphere priming effect induced by grassland species. Soil Biol Biochem 80:146-155. doi:10.1016/j.soilbio.2014. 09.023

Smithson JB, Lenne' JM (1996) Varietal mixtures: a viable strategy for sustainable productivity in subsistence agriculture. Ann Appl Biol 128:127-158. doi:10.1111/j.1744-7348.1996.tb07096.x

Spehn EM, Scherer-Lorenzen M, Schmid B, Hector A, Caldeira MC et al (2002) The role of legumes as a component of biodiversity in a cross-European study of grassland biomass nitrogen. Oikos 98: 205-218. doi:10.1034/j.1600-0706.2002.980203.x

Sprague GF, Tatum LA (1942) General vs. specific combining ability in single crosses of corn. J Am Soc Agron 34:923-932

Strauss SY, Rudgers JA, Lau JA, Irwin RE (2002) Direct and ecological costs of resistance to herbivory. Trends Ecol Evol 17(6):278-285. doi:10.1016/S0169-5347(02)02483-7

Swanston JS, Gacek E, Guy DC, Newton AC (2000) Malting performance of barley cultivar mixtures from the UK and Poland. J Inst Brew 106:239-244. doi:10.1002/j.2050-0416.2000.tb00063.x

Tester M, Langridge P (2010) Breeding technologies to increase crop production in a changing world. Science 327:818-822. doi:10. 1126/science. 1183700 
Tilman D, Downing JA (1994) Biodiversity and stability in grasslands. Nature 367:363-365. doi:10.1007/978-1-4612-4018-1_1

Tilman D, Wedin D, Knops J (1996) Productivity and sustainability influenced by biodiversity in grassland ecosystems. Nature 379:718720. doi:10.1038/379718a0

Tilman D, Knops J, Wedin D, Reich P, Ritchie M et al (1997) The influence of functional diversity and composition on ecosystem processes. Science 277:1300-1302. doi:10.1126/science.277.5330.1300

Tilman D, Cassman KG, Matson PA, Naylor R, Polasky S (2002) Agricultural sustainability and intensive production practices. Nature 418:671-677. doi:10.1038/nature01014

Tooker JF, Frank SD, Steffan-Dewenter I (2012) Genotypically diverse cultivar mixtures for insect pest management and increased crop yields. J Appl Ecol 49(5):974-985. doi:10.1111/j.1365-2664.2012. 02173.x

Violle C, Navas ML, Vile D, Kazakou E, Fortunel C et al (2007) Let the concept of trait be functional! Oikos 116:882-892. doi:10.1111/j. 0030-1299.2007.15559.x

Weiner J (1990) Asymmetric competition in plant populations. Trends Ecol Evol 5(11):360-364. doi:10.1016/0169-5347(90)90095-U

Wilson GWT, Hartnett DC, Rice CW (2006) Mycorrhizal-mediated phosphorus transfer between tallgrass prairie plants Sorghastrum nutans and Artemisia ludovician. Func Ecol 20(3):427-435. doi:10.1111/j. 1365-2435.2006.01134.x

Wimp GM, Young WP, Woolbright SA, Martinsen GD, Keim P et al (2004) Conserving plant genetic diversity for dependent animal communities. Ecol Lett 7(9):776-780. doi:10.1111/j.1461-0248. 2004.00635.x

Wissuwa M, Mazzola M, Picard C (2008) Novel approaches in plant breeding for rhizosphere-related traits. Plant Soil 321(1-2):409430. doi:10.1007/s11104-008-9693-2

Witcombe JR, Hollington PA, Howarth CJ, Reader S, Steele KA (2008) Breeding for abiotic stresses for sustainable agriculture. Phil Trans R Soc B 363:703-716. doi:10.1098/rstb.2007.2179
Wolfe MS (1985) The current status and prospects of multiline cultivars and variety mixtures for disease resistance. Ann Rev Phytopath 23: 251-273. doi: 10.1146/annurev.py.23.090185.001343

Xu S, Zhu D, Zhang Q (2014) Predicting hybrid performance in rice using genomic best linear unbiased prediction. Proc Natl Acad Sci U S A 111:12456-12461. doi:10.1073/pnas.1413750111

Yachi S, Loreau M (1999) Biodiversity and ecosystem productivity in a fluctuating environment: the insurance hypothesis. Proc Natl Acad Sci U S A 96:1463-1468. doi:10.1073/pnas.96.4.1463

Zavaleta ES, Pasari JR, Hulvey KB, Tilman GD (2010) Sustaining multiple ecosystem functions in grassland communities requires higher biodiversity. Proc Natl Acad Sci U S A 107(4):1443-1446. doi:10. 1073/pnas.0906829107

Zeller SL, Kalinina O, Flynn DFB, Schmid B (2012) Mixtures of genetically modified wheat lines outperform monocultures. Ecol Appl 22(6): $1817-1826$

Zhang W, Ricketts TH, Kremen C, Carney K, Swinton SM (2007) Ecosystem services and dis-services to agriculture. Ecol Econ 64(2):253-260. doi:10.1016/j.ecolecon.2007.02.024

Zhang X, Pérez-Rodríguez P, Semagn K, Beyene Y, Babu R et al (2015) Genomic prediction in biparental tropical maize populations in water-stressed and well-watered environments using low-density and GBS SNPs. Heredity 114:291-299. doi:10.1038/hdy.2014.99

Zhu Y, Chen H, Fan J, Wang Y, Li Y et al (2000) Genetic diversity and disease control in rice. Nature 406:718-722. doi:10.1038/35021046

Zhu J, van der Werf W, Anten NP, Vos J, Evers JB (2015) The contribution of phenotypic plasticity to complementary light capture in plant mixtures. New Phytol 207(4):1213-1222. doi:10.1111/nph.13416

Zuppinger-Dingley D, Schmid B, Petermann JS, Yadav V, De Deyn GB et al (2014) Selection for niche differentiation in plant communities increases biodiversity effects. Nature 515(7525):108-111. doi:10. 1038/nature 13869 